\title{
Article \\ A Systems Approach to Interrogate Gene Expression Patterns in African American Men Presenting with Clinically Localized Prostate Cancer
}

\author{
Gary Hardiman $1,2, * \mathbb{D}$, Stephen J. Savage ${ }^{3,4,5}$, E. Starr Hazard ${ }^{6}\left(\mathbb{D}\right.$, Willian A. da Silveira ${ }^{2}{ }^{(}$, Rebecca Morgan ${ }^{2}$, \\ Adam Harris ${ }^{2}$, Melanie S. Jefferson ${ }^{7}$, Robert C. Wilson ${ }^{8}$, Susan Caulder ${ }^{4}$, Linda Ambrose ${ }^{4}$, Lewis Frey ${ }^{9,10}$, \\ Bethany Wolf ${ }^{10}{ }^{\oplus}$, Sebastiano Gattoni-Celli ${ }^{4,5}$ and Chanita Hughes Halbert $7,11,12,13, *$
}

Citation: Hardiman, G.; Savage, S.J.; Hazard, E.S.; da Silveira, W.A.; Morgan, R.; Harris, A.; Jefferson, M.S.; Wilson, R.C.; Caulder, S.; Ambrose, L.; et al. A Systems Approach to Interrogate Gene Expression Patterns in African American Men Presenting with Clinically Localized Prostate Cancer. Cancers 2021, 13, 5143. https://doi.org/10.3390/ cancers 13205143

Academic Editor: Young E. Whang

Received: 19 August 2021

Accepted: 27 September 2021

Published: 14 October 2021

Publisher's Note: MDPI stays neutral with regard to jurisdictional claims in published maps and institutional affiliations.

Copyright: (c) 2021 by the authors. Licensee MDPI, Basel, Switzerland. This article is an open access article distributed under the terms and conditions of the Creative Commons Attribution (CC BY) license (https:// creativecommons.org/licenses/by/ $4.0 /)$.
1 Department of Medicine, Medical University of South Carolina (MUSC), Charleston, SC 29425, USA

2 Faculty of Medicine, Health and Life Sciences, School of Biological Sciences and Institute for Global Food Security, Queens University Belfast, Stranmillis Road, Belfast BT9 5AG, UK; willian.dasilveira@staffs.ac.uk (W.A.d.S.); rmorgan21@qub.ac.uk (R.M.); adam.harris@qub.ac.uk (A.H.)

3 Department of Urology, Medical University of South Carolina (MUSC), Charleston, SC 29425, USA; savages@musc.edu

4 Ralph H. Johnson VA Medical Center, Charleston, SC 29401, USA; caulder@musc.edu (S.C.); ambrosel@musc.edu (L.A.); Sebastiano.Gattoni-Celli@bms.com (S.G.-C.)

5 Department of Radiation Oncology, Medical University of South Carolina (MUSC), Charleston, SC 29425, USA

6 Academic Affairs Faculty, Medical University of South Carolina (MUSC), Charleston, SC 29425, USA; hazardes3@gmail.com

7 Hollings Cancer Center, Medical University of South Carolina (MUSC), Charleston, SC 29425, USA; sweatma@musc.edu

8 Department of Pathology and Laboratory Medicine, Medical University of South Carolina (MUSC), Charleston, SC 29425, USA; relaxingbob@gmail.com

9 Biomedical Informatics Center (BMIC), Medical University of South Carolina (MUSC), Charleston, SC 29425, USA; frey@musc.edu

10 Department of Public Health Sciences, Medical University of South Carolina (MUSC), Charleston, SC 29425, USA; wolfb@musc.edu

11 Department of Psychiatry \& Behavioral Sciences, Medical University of South Carolina (MUSC), Charleston, SC 29425, USA

12 Department of Population and Public Health Sciences, University of Southern California, Los Angeles, CA 90032, USA

13 Norris Comprehensive Cancer Center, University of Southern California, Los Angeles, CA 90033, USA

* Correspondence: g.hardiman@qub.ac.uk (G.H.); hughesha@musc.edu (C.H.H.)

Simple Summary: Men of African origin have a 2-3 times greater chance of developing prostate cancer than those of European origin, and of patients that are diagnosed with the disease, men of African descent are 2 times more likely to die compared to white men. Men of African origin are still greatly underrepresented in genetic studies and clinical trials. This, unfortunately, means that new discoveries in cancer treatment are missing key information on the group with a greater chance of mortality. The objective of this study was to increase our knowledge of prostate cancer in men undergoing a prostate biopsy. We carried out RNA sequencing of biopsy specimens and examined racial differences in prostate gene expression. A gene expression signature was uncovered which separated the men based on their race. Furthermore, within men of African descent this signature separated men with the most severe clinical characteristics.

Abstract: An emerging theory about racial differences in cancer risk and outcomes is that psychological and social stressors influence cellular stress responses; however, limited empirical data are available on racial differences in cellular stress responses among men who are at risk for adverse prostate cancer outcomes. In this study, we undertook a systems approach to examine molecular profiles and cellular stress responses in an important segment of African American (AA) and European American (EA) men: men undergoing prostate biopsy. We assessed the prostate transcriptome with a single biopsy core via high throughput RNA sequencing (RNA-Seq). Transcriptomic analyses 
uncovered impacted biological pathways including PI3K-Akt signaling pathway, Neuroactive ligandreceptor interaction pathway, and ECM-receptor interaction. Additionally, 187 genes mapping to the Gene Ontology (GO) terms RNA binding, structural constituent of ribosome, SRP-dependent cotranslational protein targeting to membrane and the biological pathways, translation, L13a-mediated translational silencing of Ceruloplasmin expression were differentially expressed (DE) between EA and AA. This signature allowed separation of AA and EA patients, and AA patients with the most severe clinical characteristics. AA patients with elevated expression levels of this genomic signature presented with higher Gleason scores, a greater number of positive core biopsies, elevated dehydroepiandrosterone sulfate levels and serum vitamin D deficiency. Protein-protein interaction (PPI) network analysis revealed a high degree of connectivity between these 187 proteins.

Keywords: stress; precision medicine; RNA-Seq; prostate; health disparities; African American; vitamin D; transcriptomics; health disparities

\section{Introduction}

Stress occurs when a person cannot cope efficiently with the daily physical or psychological demands placed on the body [1-4]. The primary hormonal stress mediators, catecholamines and glucocorticoids, elicit both beneficial and harmful effects. In the short term, they are required for allostasis, adaptation, cellular homeostasis, and survival. However, over an extended period, this leads to 'allostatic load' first defined by McEwen and Stellar [5] that can accelerate disease processes including cancer [6]. Allostatic load indicates disruption of biological processes in response to psychological and social stress. It is used as a marker of how much psychological and social stressors impact biological functioning [7-9]. Allostatic load values reflect chronic, steady state levels of stress as well as failure to terminate responses to acute stressors [10,11].

According to the National Center for Health Statistics (2013), men from racial minority groups continue to experience poor health outcomes compared to non-minority men. For instance, the life expectancy for African American (AA) men is significantly lower compared to the expectancy for white men. Precision medicine can play a significant role in reducing racial disparities in morbidity and mortality among minority men because these efforts are designed to individualize health care based on biological, behavioral, and social factors that contribute to disease risks and enhance health outcomes. However, the development and implementation of approaches for precision medicine is still limited among minority men because empirical data are lacking on the ways in which risk factors and protective variables work in this underserved population.

From a global perspective prostate cancer is among the most frequently diagnosed malignancies among men. In the United States it is the second leading cause of cancer-related mortality. Although its incidence has declined in recent years, overall prostate cancerrelated mortality among AA men has increased [12-14]. Epidemiological studies suggest that AA men have greater prostate cancer incidence, morbidity, and mortality of compared to European-Americans (EA) [15]. The origin and causes of racial disparities in prostate cancer risk and outcomes remain to be fully elucidated. However, it is well established that socioeconomic and behavioral factors both contribute to disease progression. Distrust in the health care system and fear associated with detection and treatment have also been listed as reasons for late diagnosis in AA men [14]. Reduced access to health care services is a contributor, but even when access to health care systems is comparable in EA and AA men such as the Veterans Administration (VA), AA exhibit elevated serum PSA values and higher-grade tumors than EA even when the identical disease stage is considered [16,17]. Thus, access to medical care is essential but not adequate for eradicating racial disparities in prostate cancer outcomes.

Racial differences are common among cancers, examples include multiple myeloma, colorectal and breast cancer. Multiple myeloma is the most common hematologic cancer 
in patients of African descent [18]. Although it is a rare disease, diagnoses are twice as high in patients of African descent compared to European descent. Reasons for these differences are currently unknown and the disease remains uncurable [19-21]. In the USA, colorectal cancer patients of African descent experience decreased stage specific survival in comparison to patients of European descent irrespective of socioeconomical background, age, treatment, and stage at diagnosis [22]. Invasive breast cancer mortality rates also differ between patients of African and Northern European descent. In the USA, African American women are more likely to die from the disease than EuropeanAmerican women [23]. African American women also experience worse prognosis and decreased survival times compared to European-American women regardless of their socioeconomical background, age, and stage at diagnosis [24].

Prostate cancer (PC) has one of the greatest racial disparities among cancer types. In the U.S.A., African Americans have among the highest mortality and lowest survival rates of any race or ethnic group [25]. PC is also the top cause of cancer mortality among men of African descent living in Caribbean and Sub-Saharan Africa [26]. Similar disparities exist in the UK, where men of African descent are 2-3 times more likely to develop PC than white men and have a $30 \%$ higher mortality rate [27]. Non biological factors contributing to PC racial disparities include diminished societal trust in the medical community, level of education attained, and financial concerns. Access to healthcare plays an important role in PC mortality. However, African American men have higher PSA values and higher tumor grades even at the same cancer stage, compared with non-African American men within the same healthcare system such as the Veterans Administration in the USA [28]. The reasons underlying these racial differences remain an area of active research. Many biological explanations have been considered including dietary factors such as alcohol and nicotine intake, vitamin D deficiency and lycopene and isoflavone consumption [28-32]. African Americans have higher rates of variations in tumor suppressor genes such as $E P H B 2$ and are susceptible to higher prevalence of chromosome $8 \mathrm{q} 24$ variants which are linked with prostate cancer [33-38].

Racial differences in prostate cancer outcomes reflect racial variations in vitamin $D$ levels [39]. Several studies have shown that approximately $60 \%$ of AA men have suboptimal levels of circulating 25(OH)D [40,41]. Our research team previously demonstrated that supplementation with vitamin D3 eradicates racial differences in serum levels of 25(OH)D [42-44]. We previously carried out a systems level analysis of the prostate transcriptome in a cohort of AA men and EA men who had undergone a prostatectomy, following a diagnosis of localized prostate cancer. [28]. In this sample of 27 subjects (10 AA and $17 \mathrm{EA}$ ) who were randomized to vitamin D3 supplementation or placebo prior to surgical treatment, AA men exhibited increased expression of immune response and inflammatory related genes, suggesting that inflammation may contribute to disease development in AA. These inflammatory transcripts were modulated with vitamin D3 supplementation. This initial study revealed the existence of fundamental biological differences within the prostate between AA and EA men with prostate cancer.

In the absence of androgen receptor (AR) signaling, the glucocorticoid receptor (GR) is a major contributor to disease progression and drug resistance in prostate cancer. The consequences of glucocorticoid-activated GR signaling mediating protein expression related to tumor progression and drug resistance could influence patients with high endogenous cortisol levels or a susceptibility to GR signaling such as AA patients. A recent study based on AA patient derived cell lines indicated that glucocorticoid signaling is an important aspect of prostate cancer health disparities [45].

In this study, we examined molecular profiles and cellular stress responses in an important segment of AA and EA men: men undergoing prostate biopsy. The primary goal in the present study was to demonstrate the ability to assess the prostate transcriptome with a single biopsy core in a new patient cohort presenting with or at risk for early-stage prostate cancer. This information could guide precision medicine approaches tailored specifically for AA men. High throughput RNA sequencing (RNA-Seq) was performed, 
and analyses compared across racial groups. An additional goal of the present study was to correlate relevant health parameters of patients undergoing a core biopsy with the molecular profiles obtained from prostate tissue samples. This objective was consistent with increasing evidence that pro-inflammatory mechanisms and the hypothalamic pituitary adrenal axis are key mediators of the physiological stress or allostatic load, and previous work from this group which highlighted a molecular signature of inflammation in the AA prostate of men who have undergone a prostatectomy [28]. This study was approved by the Institutional Review Board at the Ralph H. Johnson Veteran's Affairs Medical Center.

\section{Results}

\subsection{Patient Cohort}

We enrolled $33 \mathrm{AA}$ and $27 \mathrm{EA}$ men, 60 subjects in total, who had undergone a prostate biopsy. Table 1 provides the characteristics of the subjects, distributions of their age and race, body mass Index (BMI), serum levels of $25(\mathrm{OH}) \mathrm{D} 3$, blood pressure, total cholesterol, serum Hemoglobin A1C (HBA1C) levels, blood prostate specific antigen (PSA) levels and the number of positive prostate biopsy cores. For these patients, data on comorbidities, including presence of coronary artery disease, hypertension, hypercholesterolemia, diabetes mellitus, depression, and post-traumatic stress disorder and whether they had performed military service were obtained. Finally, data on whether the patients were supplementing with multivitamins or not was gathered.

Table 1. Patient demographics and measured clinical variables.

\begin{tabular}{|c|c|c|c|c|c|c|c|c|c|}
\hline & \multicolumn{3}{|l|}{ Overall $n=60$} & \multicolumn{3}{|c|}{$\begin{array}{l}\text { African Americans N (\%) } \\
\qquad 33(55 \%)\end{array}$} & \multicolumn{3}{|c|}{$\begin{array}{c}\text { Caucasians N (\%) } \\
27(45 \%)\end{array}$} \\
\hline & Median (IQR) & Minimum & Maximum & Median (IQR) & Minimum & Maximum & Median (IQR) & Minimum & Maximum \\
\hline Age, Years & $65(6)$ & 46 & 76 & $65(5)$ & 46 & 76 & $65.5(7)$ & 46 & 75 \\
\hline \multirow{2}{*}{ Blood Pressure, mmHg } & SBP: 135 (33) & 109 & 183 & SBP: 137 (23) & 109 & 183 & SBP:130 (34) & 112 & 170 \\
\hline & DBP: $82(12)$ & 62 & 100 & DBP: 84 (16) & 66 & 100 & DBP: 79.5 (12) & 62 & 98 \\
\hline Body Mass Index, kg/m² & $29.2(7.6)$ & 17.8 & 52.1 & $29.1(7.5)$ & 14.8 & 52.1 & $29.4(7.4)$ & 22.1 & 37.4 \\
\hline Vitamin D (ng/mL) & $28(11.1)$ & 4.8 & 68.6 & $22.6(18.6)$ & 4.8 & 63.3 & $32.5(14.7)$ & 11.1 & 68.6 \\
\hline Total cholesterol (mg/dL) & $189(51)$ & 85 & 271 & $201(42)$ & 85 & 271 & $174.5(33)$ & 109 & 257 \\
\hline HBA1C Level \% & $5.6(0.7)$ & 4.1 & 10.5 & $5.7(0.7)$ & 4.1 & 10.5 & $5.45(0.7)$ & 4.6 & 9.2 \\
\hline PSA $(\mu \mathrm{g} / \mathrm{L})$ & $6.21(3.27)$ & 0.56 & 31.5 & $6.12(2.40)$ & 1.7 & 31.5 & $6.47(3.30)$ & 0.56 & 20.3 \\
\hline Grade & $6(7)$ & 0 & 9 & $6(1)$ & 0 & 9 & $0(6)$ & 0 & 9 \\
\hline Number Positive cores & $1(4)$ & 0 & 12 & $3(5)$ & 0 & 12 & $0(1)$ & 0 & 4 \\
\hline
\end{tabular}

\subsection{Differential Prostate Gene Expression between African American and European American Patients}

We set EA subjects (27 samples) as the control and AA subjects (33 samples) as test cases. These data were analyzed to identify race-associated differences in prostate gene expression. In order to assess if the study had sufficient power, we utilized the sample size tool available in RNASeqPower [46]. Power estimation depends on read depth or counts, the associated coefficient of variation (CV) of counts within conditions, fold change (FC) i.e., the effect size, the type I error rate, and the group sample size [47,48]. CVs of 0.1 and 0.4 are typically recommended for inbred (laboratory models) and outbred (human) models, respectively and the sequencing read depth was set at 50 reads per transcript. Figure $1 \mathrm{~A}, \mathrm{~B}$ display power as a function of $\mathrm{CV}$, using 27 and 32 replicates respectively to detect FC values ranging from 2.0 to 3.0. Type I error rate was conservatively fixed at $\alpha=2.5 \times 10^{-6}$ $(\alpha=0.05$ after Bonferroni Correction). From this analysis we concluded that have at least $90-97 \%$ power to detect $\mathrm{DE}$ transcripts even for $\mathrm{FC}=2$ and $\mathrm{CV}=0.4$ with read counts of at least 50 . 
A

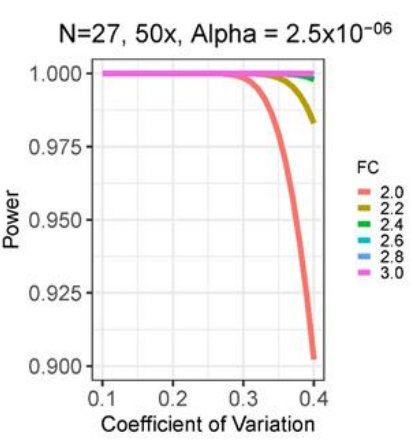

B

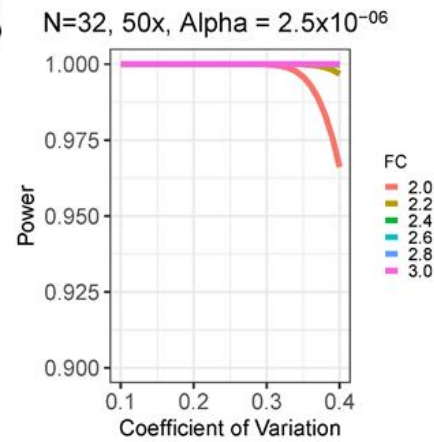

\section{C}$$
\text { (2) }
$$

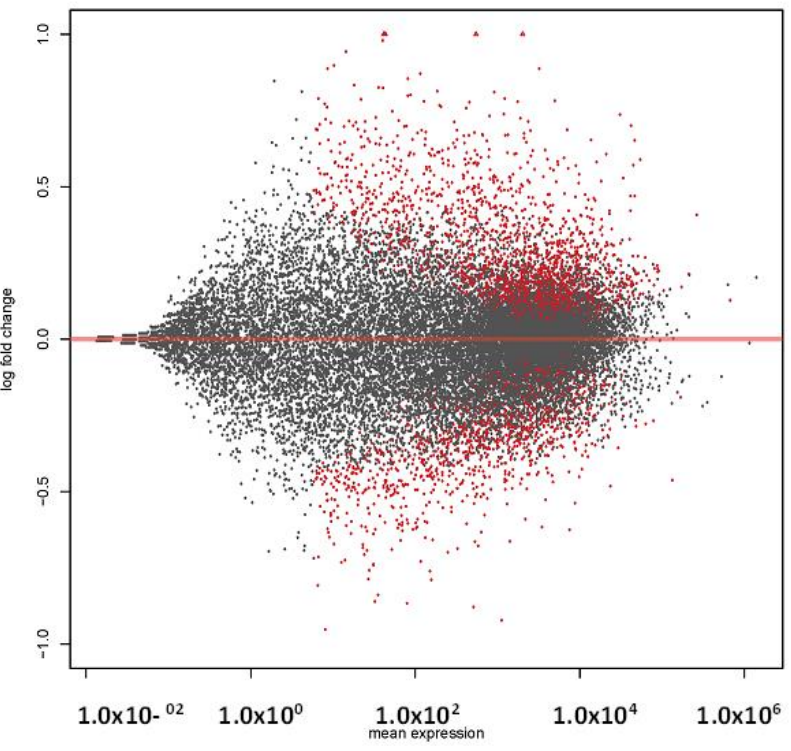

D

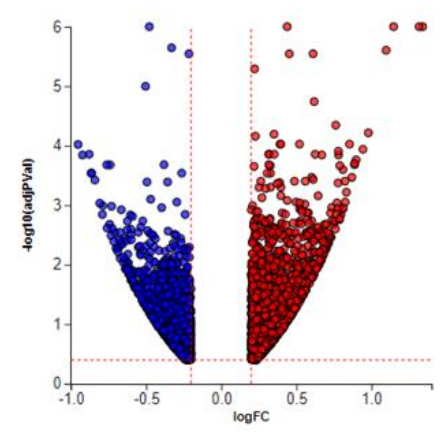

Figure 1. Power analysis plots with power as a function of the co-efficient of variation (CV), using (A): 27 and (B): 32 replicates respectively to detect FC values ranging from 2.0 to 3.0. Type I error rate is conservatively fixed at $\alpha=2.5 \times 10^{-6}$ ( $\alpha=0.05$ after Bonferroni Correction). (C) MA Plot examining differential gene expression between EA and AA men. The plot visualizes the differences between measurements taken in two samples, by transforming the data onto $\mathrm{M}$ (log ratio) and $\mathrm{A}$ (mean average) scale. $\mathrm{M}$ (Y-axis) is plots differential gene expression (log2 (EA/AA). A (X-axis) plots transcript abundance $(0.5 \log 2 \mathrm{AA}+0.5 \log 2 \mathrm{EA})$. significant transcripts $(q<0.1)$ are highlighted in red. (D) Volcano plot depicting the DE genes in the contrast between AA and EA men. The horizontal axis is the log fold change, and the vertical axis is the negative base-10 logarithm of the adj $p$-value or $q$-value. The red-dotted lines represent the threshold. The up-regulated genes (positive log fold change) are shown in red, while the down-regulated genes are blue. AA: African-American; EA: European-American.

This power analysis is extremely conservative as we identified differentially expressed (DE) transcripts based on false discovery rate (FDR) (Figure 1C,D). Also, our earlier study on a smaller patient cohort was sufficiently powered to uncover differences in prostate gene expression between AA and EA men [28]. FC estimation and significance testing were performed using DESeq2 [49]. As the patient biopsy material was sampled at different times of the year and the sequencing was done using two Illumina flow cells, we included these potential confounders as a batch factor in the DEseq2 analyses. For each gene, DESeq2 provided a FC, and an adjusted $p$ (adj- $p$ ) or $q$-value equal to the smallest FDR incurred.

When we compared prostate gene expression between AA and EA subjects, this revealed 3277 significantly DE genes with $q<0.1$ out of a total of 18,797 genes with measured expression (Figure 2).

To identify gene signaling network perturbations in the prostate between EA and AA men we utilized iPathwayGuide [50]. To ensure we included all genes that together enrich gene ontology (GO) terms or biological pathways we relaxed the FDR significance threshold to $q<0.4$ and required a minimum absolute log fold change in expression of 0.2. Pathways were then scored using the Impact Analysis method. Significant pathways were ranked by their unique pathway-specific adjusted $p$-value. 
3,224 genes significantly differentially expressed at FDR $<0.1$ in the prostate

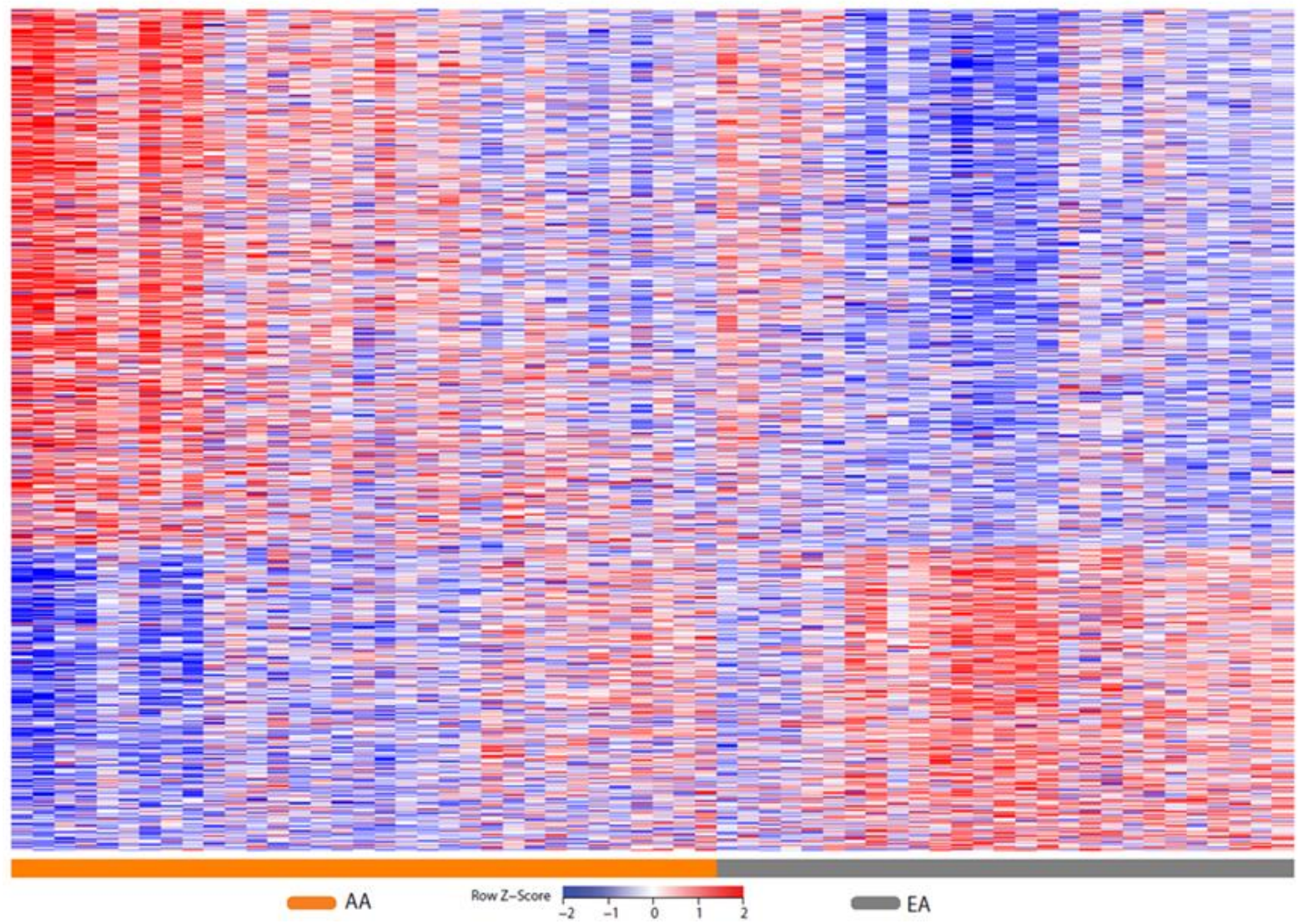

Figure 2. Heat map of gene expression changes by race. Red and blue boxes depict relative over- and under-expression with regard to a reference set as the mid-point between all patients. Only significant transcripts $(q<0.1)$ are shown. AA: African-American; EA: European-American.

Significant (FDR corrected) pathways identified included Nicotine addiction $q=7.64 \times 10^{-6}$, Neuroactive ligand-receptor interaction $q=1.01 \times 10^{-3}$, Taste transduction $q=1.04 \times 10^{-3}$, Olfactory transduction $q=1.48 \times 10^{-3}$, ECM-receptor interaction $q=8.33 \times 10^{-3}$ and the PI3K-Akt signaling pathway $q=1.95 \times 10^{-3}$ (Table 2).

Table 2. Analysis of Impacted Pathways between AA and EA men.

\begin{tabular}{cl}
\hline Pathway Name & pv_fdr \\
\hline Nicotine addiction & $7.64 \times 10^{-6}$ \\
\hline Neuroactive ligand-receptor interaction & $1.01 \times 10^{-3}$ \\
\hline Taste transduction & $1.01 \times 10^{-3}$ \\
\hline Olfactory transduction & $1.48 \times 10^{-3}$ \\
\hline Arginine and proline metabolism & $1.60 \times 10^{-3}$ \\
\hline ECM-receptor interaction & $8.33 \times 10^{-3}$ \\
\hline Cell adhesion molecules (CAMs) & $8.80 \times 10^{-3}$ \\
\hline Drug metabolism-cytochrome P450 & $1.95 \times 10^{-2}$ \\
\hline Alcoholism & $1.95 \times 10^{-2}$ \\
\hline PI3K-Akt signaling pathway & $1.95 \times 10^{-2}$ \\
\hline
\end{tabular}


The phosphatidylinositol 3'-kinase (PI3K)-Akt signaling pathway is activated by various cellular stimuli and toxins. It regulates basic cellular processes including transcription, translation, proliferation, growth, and survival (Figure 3, Table 2).

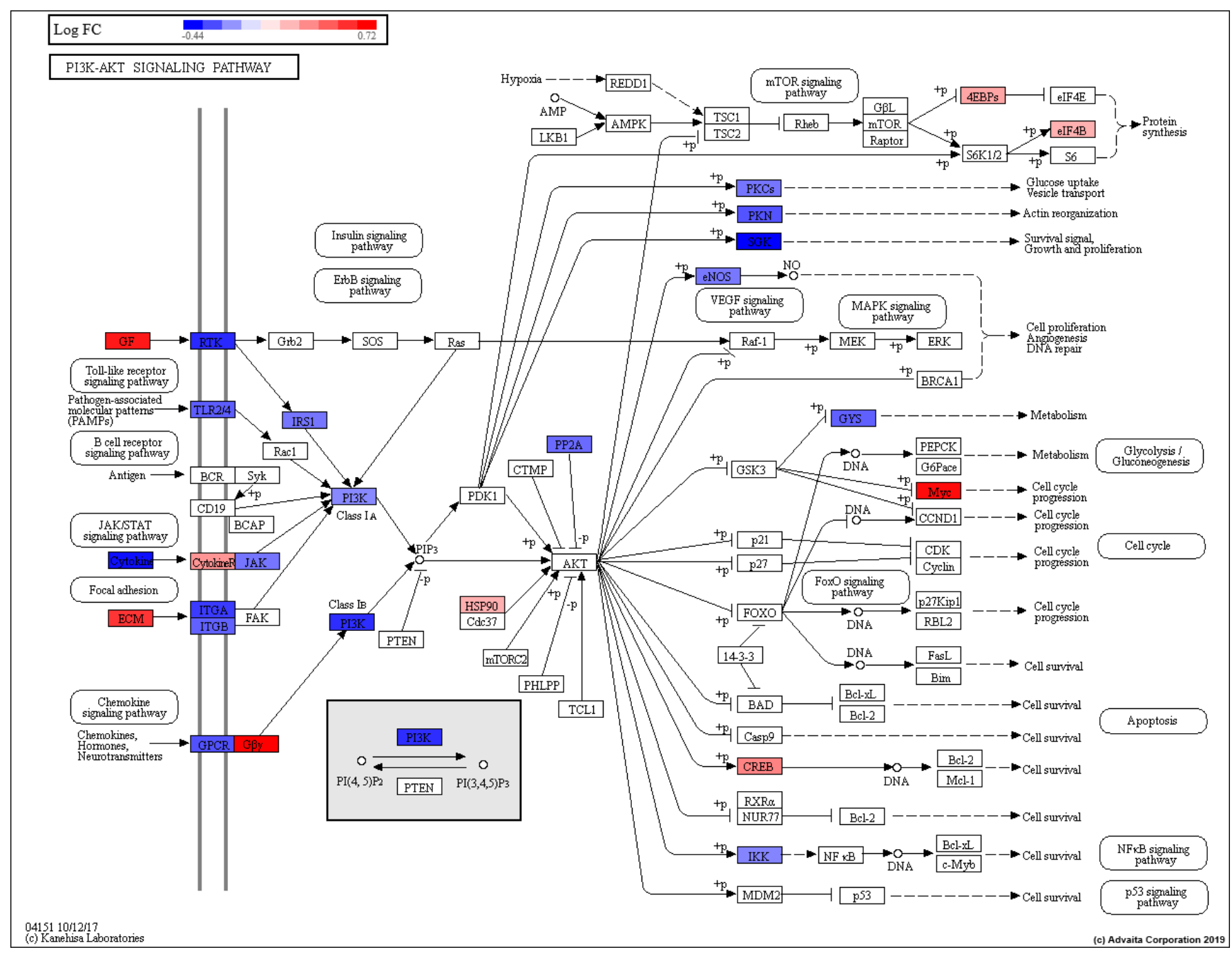

Figure 3. PI3K-Akt signaling pathway (KEGG: 04151) pathway genes showing gene regulation based on EA vs. AA prostate DE analysis (EA is control, AA is test). RED: upregulated, BLUE: downregulated.

Genes belonging to the P13K-Akt signaling pathway that were modestly upregulated among AA compared to EA men included THBS4, CREB3L1, TNN, COL4A4, COL4A3, COL2A1, FGF12, MYC and GNG13 (Table S1). Genes belonging to the pathway that were modestly downregulated among AA relative to EA men included SGK1, ANGPT2, FGF11, IL4, IL6, ANGPT4, THBS2, FLT4, NTRK2, PIK3R6, LAMA5, and MET.

The Neuroactive ligand-receptor interaction pathway comprises G-protein coupled receptors, ion channels and ligands that function in modulation of neural plasticity, memory processes, and behavior (Figure 4).

Genes belonging to the Neuroactive ligand-reception interaction pathway that were modestly upregulated in AA relative to EA men included AGTR1, F2RL2, NPY4R and GRIN3A. Genes belonging to this pathway that were modestly downregulated in AA compared to EA men included GABRP, ADORA2B, TACR1, TAAR1, GABRQ and GALR1 (Table S2). 


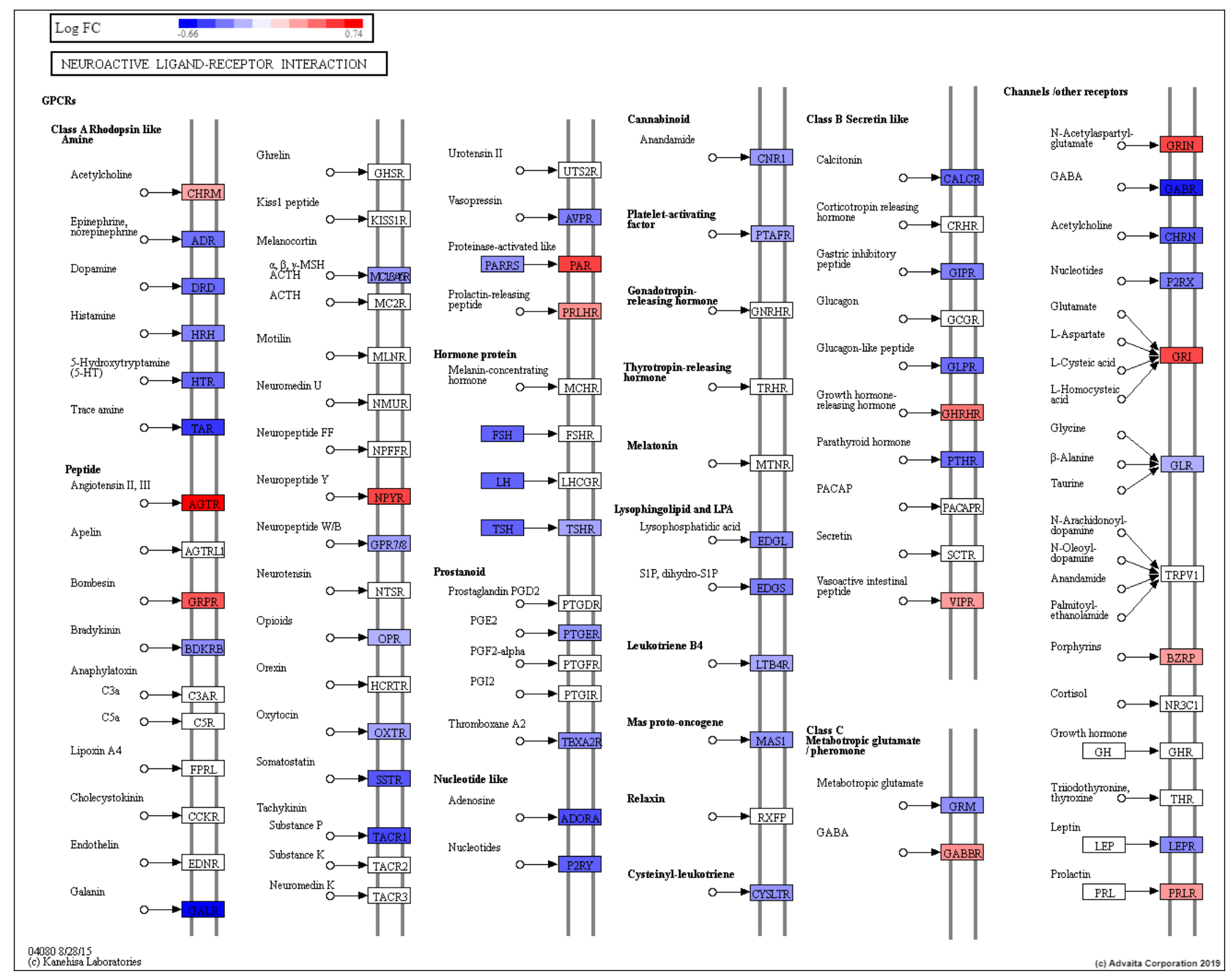

Figure 4. Neuroactive ligand-receptor interaction pathway (KEGG: 04080) showing gene regulation based on EA vs. AA prostate DE analysis (EA is control, AA is test). RED: upregulated, BLUE: downregulated.

The extracellular matrix (ECM) is a complex milieu of functional and structural macromolecules which functions in tissue and organ morphogenesis and maintains the integrity of cell and tissue structure and function (Figure 5).

Genes belonging to the ECM pathway that were modestly downregulated in EA patients included LAMA5, SV2B, THBS2, VWF, ITGA3, ITGA7 and TNXB (Table S3). Genes belonging to the ECM pathway that were modestly upregulated in EA relative to AA patients included THBS4, RELN, SPP1, COL9A2 and GP6.

Other pathways included Nicotine addiction, Taste and Olfactory transduction, and Alcoholism. Nicotine is one of the main psychoactive ingredients in tobacco that contributes to the harmful tobacco smoking habit (KEGG: 05033). Taste transduction involves how taste stimuli are detected by taste receptor cells (TRCs). Three distinct cell types are found in mammalians type I, II cells, and type III cells. Type I cells express epithelial sodium channel $(\mathrm{ENaC})$ and mediate the perception of low salt. Type II cells, function in transduction of bitter, sweet and umami taste and are mediated by a PLC-beta/IP3signaling cascade. Type III cells mediate sour taste via apically located proton-selective ion channels (KEGG: 04742). Olfactory transduction transduces binding of odorant molecules to a receptor into an electrical signal that can be transmitted to the brain (KEGG: 04740). Alcoholism, or dependence on ethanol, is a chronic relapsing disorder with significant unfavorable health outcomes (KEGG: 05034). Cell adhesion molecules (CAMs) are cell 
surface glycoproteins which play a role in many biological responses the immune response and inflammation (KEGG: 04514). Arginine and proline metabolism are central pathways involved in the biosynthesis of the arginine and proline from glutamate and liked with developmental stage and metastasis (KEGG: 00330). Drug metabolism is mediated by the cytochrome P450 enzymes (KEGG: 00982)

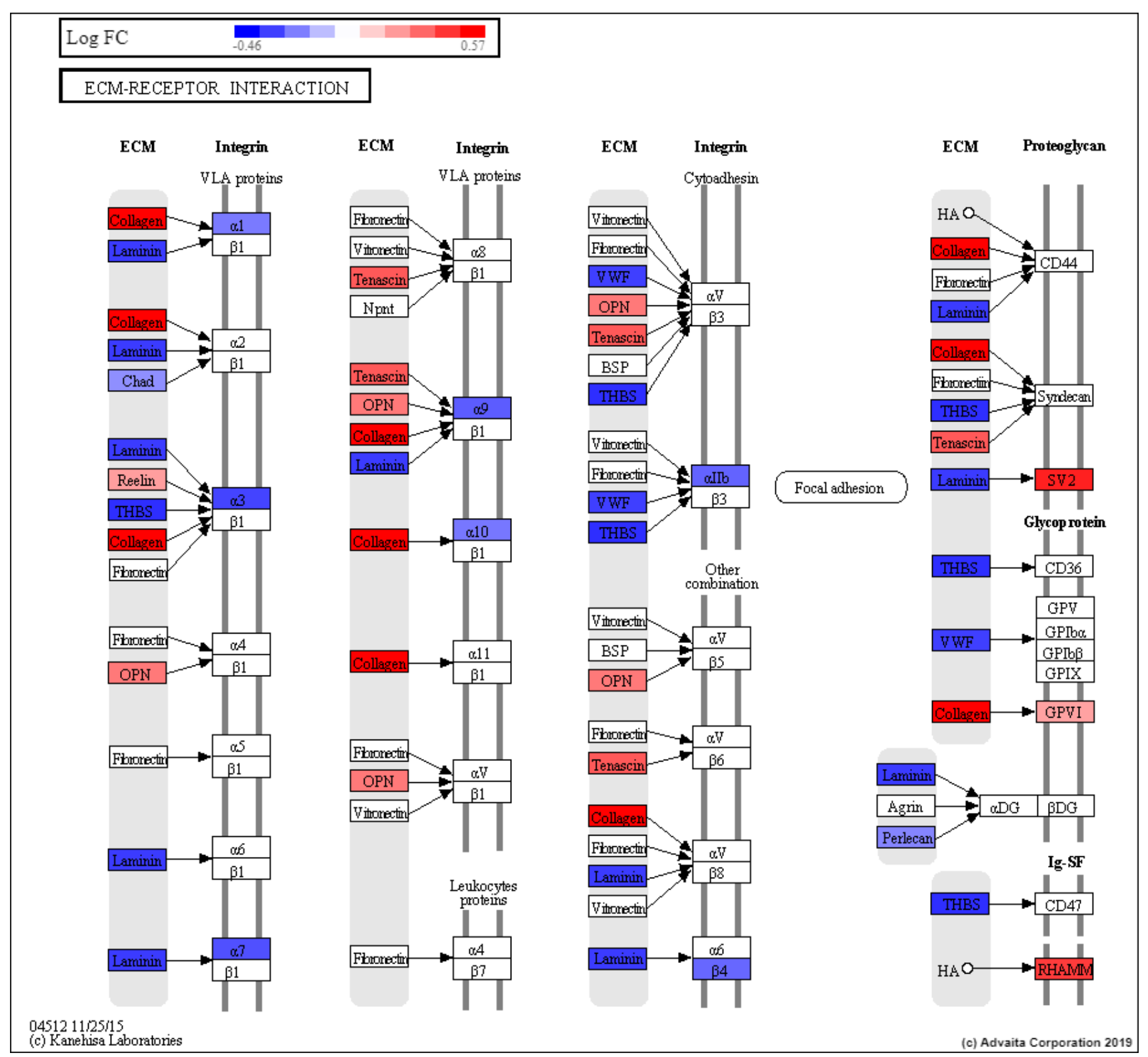

Figure 5. ECM-receptor interaction (KEGG: 04512) DE pathway genes based on EA vs. AA prostate DE analysis (EA is control, AA is test). RED: upregulated, BLUE: downregulated.

Gene list enrichment analysis was performed using ToppFunn with 3277 DE genes $(q<0.1)$ as input [51]. Of this, 3224 DE genes mapped to known transcripts. This enabled functional enrichment of the gene and uncovered significant differences (Bonferroni corrected $p$-values, $q$ ) between the two groups (Table S4).

These included the GO molecular function (MF) terms RNA binding $q=4.95 \times 10^{-10}$, and structural constituent of ribosome $q=2.79 \times 10^{-13}$, GO biological process (BP) term SRP-dependent co-translational protein targeting to membrane $q=4.99 \times 10^{-16}$, the biological pathways translation $q=1.42 \times 10^{-14}$ and L13a-mediated translational silencing 
of Ceruloplasmin expression $q=2.34 \times 10^{-15}$; and the co-expression signature 'Genes up-regulated in prostate cancer samples' $q=1.73 \times 10^{-21}$ (Figure 6, Table S4).

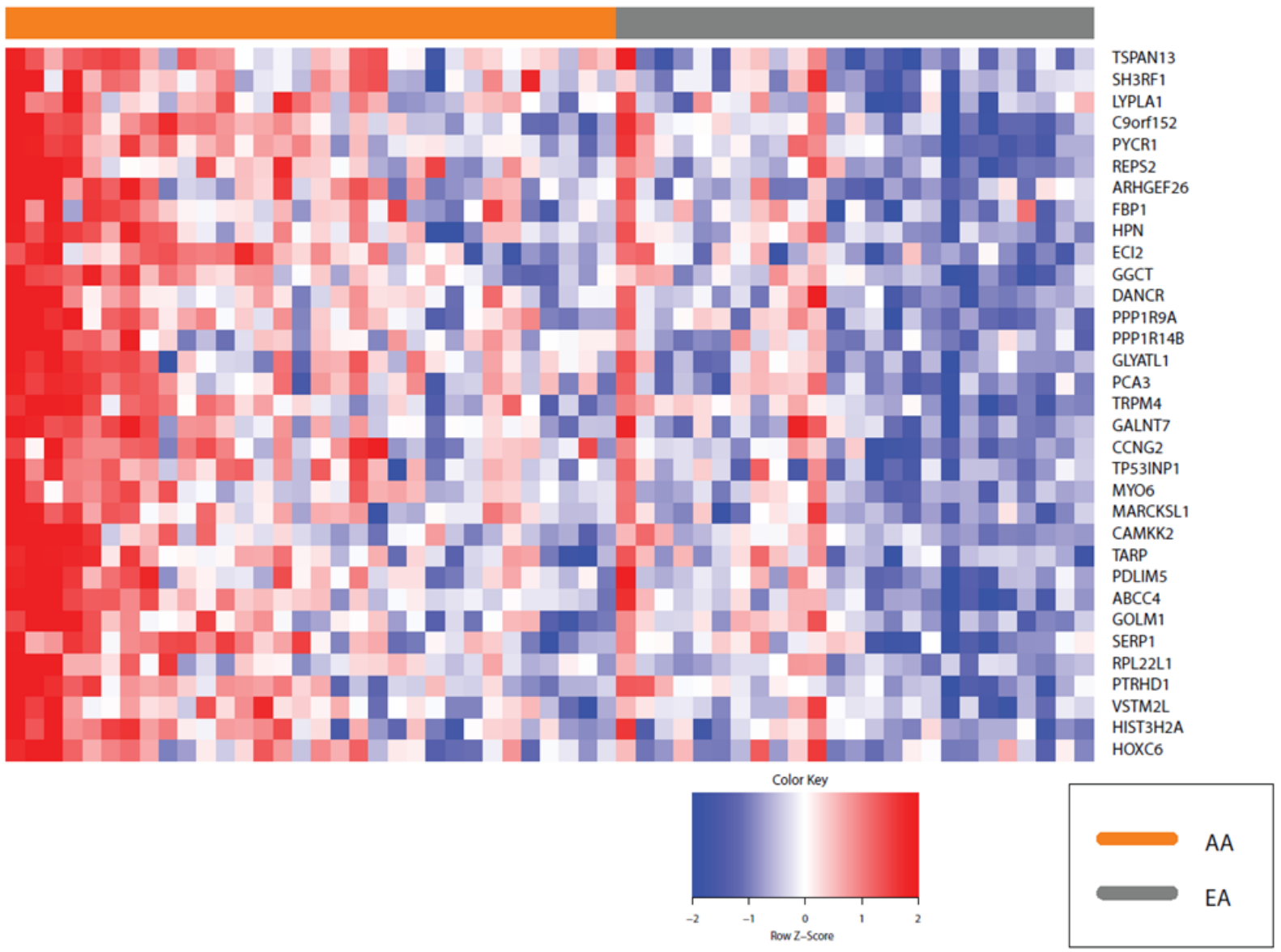

Figure 6. Heat map of gene expression changes in EA men compared with AA men for transcripts that map to the co-expression signature 'Genes up-regulated in prostate cancer samples'. Red and blue boxes depict relative over- and under-expression with regard to a reference set as the mid-point all patients. Only significant transcripts $(q<0.1)$ are shown.

We next explored the transcripts that mapped to these various GO categories described above and identified 187 transcripts, 50 of which were shared across all these categories and 96 that were unique to translation (Figure 7; Table S5). We plotted the expression of these 187 transcripts in each patient using heat maps. This revealed modest differences between AA and EA patients.

A pattern emerged in which the following transcripts were clearly downregulated in AA relative to EA patients: $\mathrm{S} 100$ calcium binding protein (S100A16), heat shock protein family B (small) member 1 (HSPB1), nuclear RNA export factor 3 (NXF3), RANBP2-like and GRIP domain containing 1 (RGPD1), apolipoprotein B mRNA editing enzyme catalytic subunit 2 ( $A P O B E C 2$ ), CUGBP Elav-like family member 3 (CELF3), piwi like RNA-mediated gene silencing 2 (PIWIL2), RNA binding motif protein 20 (RBM20), adenosine deaminase domain containing 2 (ADAD2) and ribosomal protein L23a pseudogene 7 (RPL23AP7), AHNAK nucleoprotein 2 (AHNAK2), solute carrier family 16 member 3 (SLC16A3) and Rho guanine nucleotide exchange factor 28 (ARHGEF28).

The heat map revealed a gradation of expression of the 187 transcripts across all patients with extremes observed in both AA and EA patients and a cluster of five AA patients separating from other patients (at the left of the heat-map Figure 7). Many of the prostate transcripts that were upregulated in AA were down regulated in EA and vice versa. 


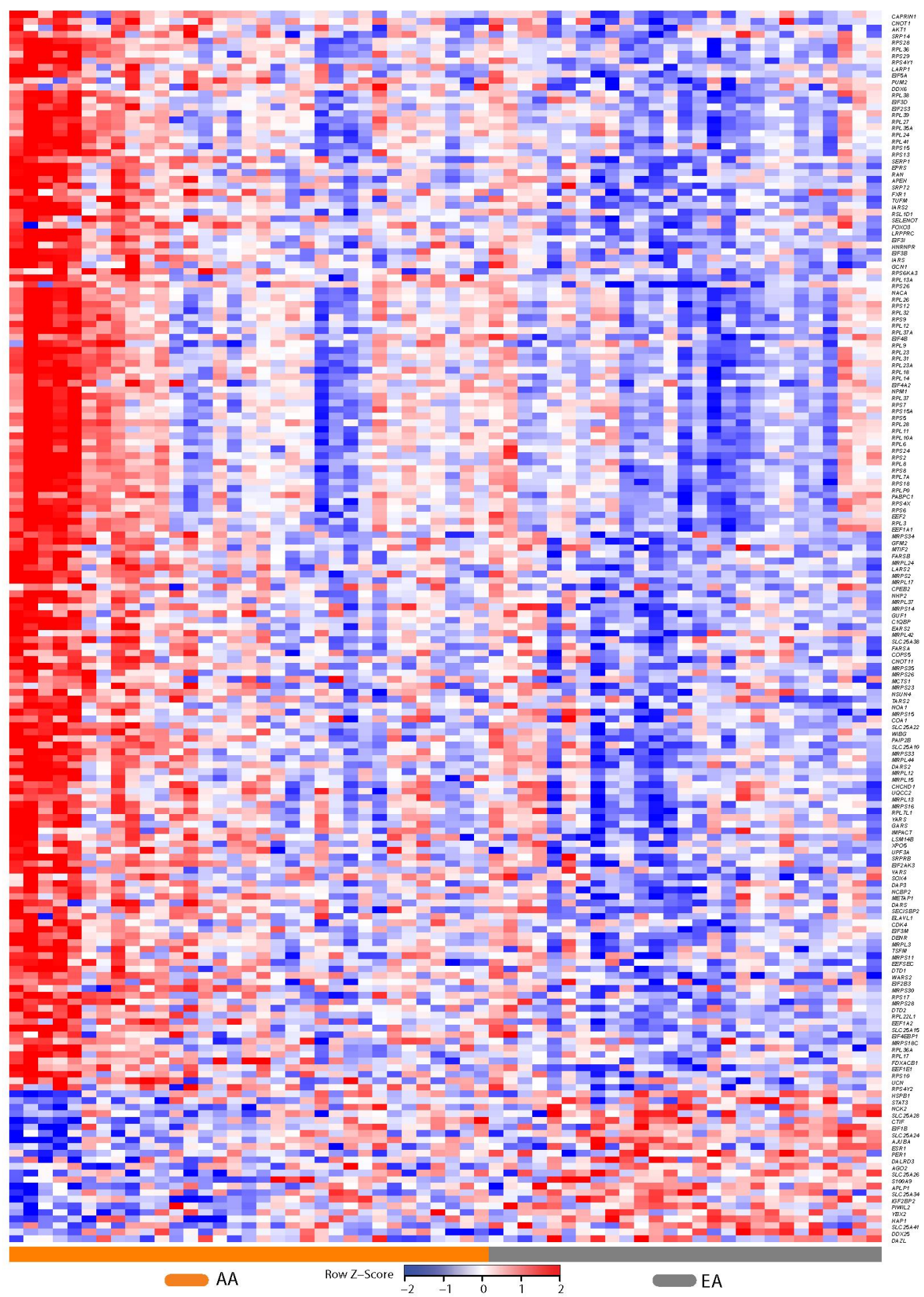

Figure 7. Heatmap of the 187 shared gene signatures derived from the GO terms RNA binding, structural constituent of ribosome, SRP-dependent co-translational protein targeting to membrane and the biological pathways translation, L13a-mediated translational silencing of Ceruloplasmin expression. Red and blue boxes depict relative over- and underexpression with regard to a reference set as the mid-point between all patients. Only significant transcripts $(q<0.1)$ are shown. A cluster of five AA patients is visible at the extreme left of the heatmap.

To interpret the relationships between the proteins encoded by these 187 transcripts we combined the gene expression data with protein-to-protein interactions (PPIs) interaction data and explored the resulting interactome (Figure 8). This analysis revealed a major PPI network comprised of most of the proteins that constitute this 187 gene signature. The high 
degree of connectivity observed in amongst these 187 genes is often seen in key signaling molecules which contribute to our understanding the molecular mechanisms of disease. This dense PPI network is suggestive of multiple protein complexes and suggestive of a functional role for these 187 proteins.

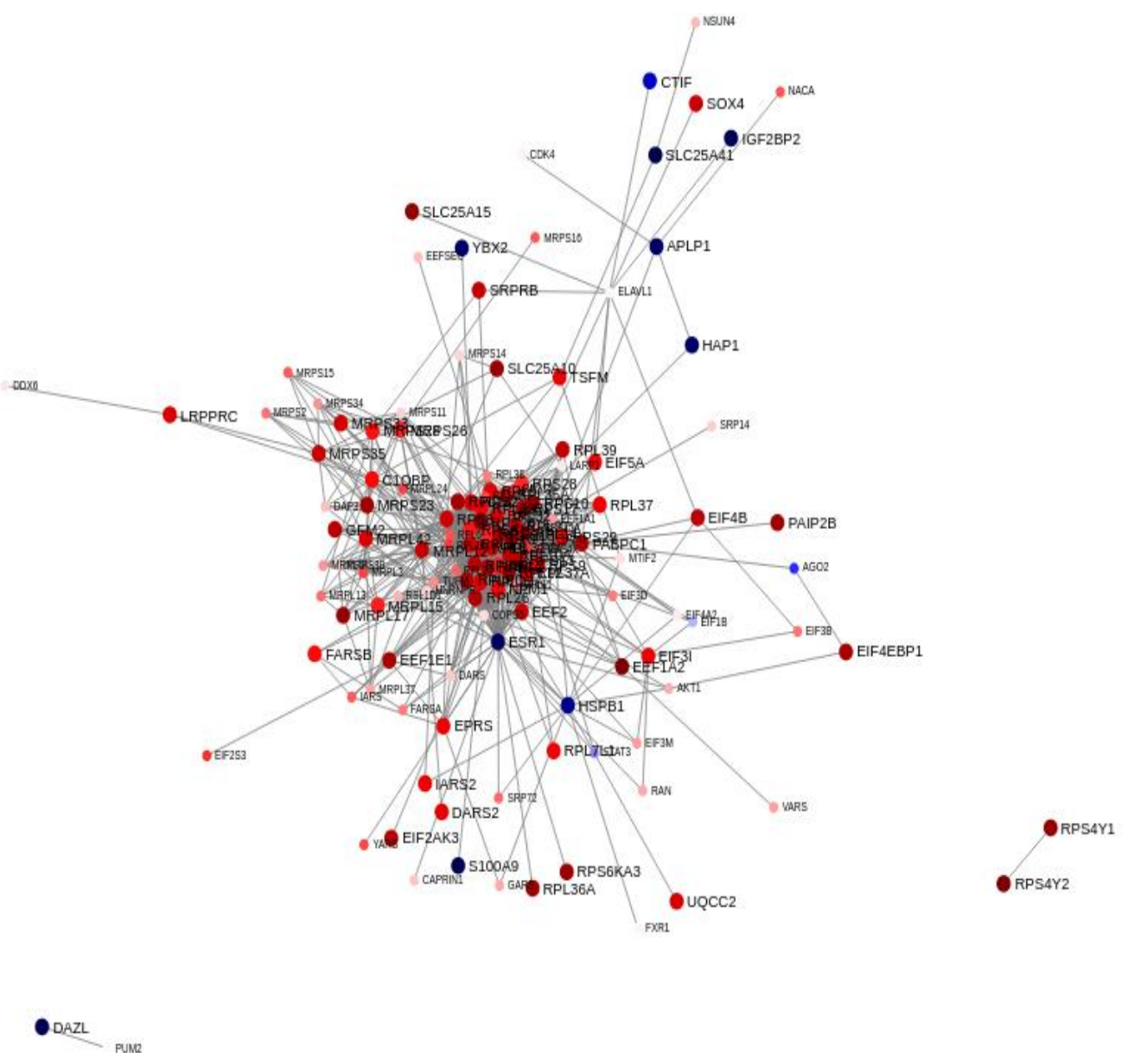

Figure 8. Interaction network of 187 signature genes using The Search Tool for Retrieval of Interacting Genes/Proteins (STRING) Protein-protein interaction (PPI) database. A node represents an individual protein and the edge connecting two nodes represents the relationship between them, i.e., they represent interacting proteins. Nodes with significantly higher degree than other nodes within a system are hub nodes. The nodal color reflects direction and size of regulation in AA men compared to EA men as defined by fold-change values from the experiment. Nodes with no interactions are excluded from the visualization.

We examined the functional roles of these 187 proteins using the ToppGene Suite portal (Table S6) [51]. This revealed that seven of these transcripts LARP1, PUM2, PABPC1, DDX6, DDX25, ELAVL1 and CAPRIN1 mapped to the GO: Cellular Component term cytoplasmic stress granule $\left(q=5.48 \times 10^{-5}\right)$. Forty-four of the encoded proteins were previously identified in yeast two-hybrid screenings of libraries from prostate epithelial cell lines using High Mobility Group B (HMGB) proteins as baits [52]. HMGB proteins are functionally related to cancer progression and HMGB1 overexpression has been detected in cancerous cells of prostate epithelial origin [53]. Eleven of these transcripts mapped to the GeneSigDB co-expression signature Human Prostate ChoVega05 $\left(q=7.57 \times 10^{-14}\right)$ [54]. Next, we examined these 187 proteins using the cBioportal for Cancer Genomics $[55,56]$. We assessed 4900 samples / 4687 patients across 14 studies encompassing prostate adenocarcinoma and prostate cancer and observed that these 187 genes were altered in $1308(28 \%)$ of queried patients and $1383(28 \%)$ of queried samples (Table S7/Figure S1) indicating that this gene signature plays a functional role in prostate cancer progression. 


\subsection{Patient Characteristics and Clinical Phenotype}

We wished to compare AA and EA patients across a range of values including age, clinical variables such as blood pressure, body mass index (BMI), serum vitamin D levels, total cholesterol, Hba1c, prostate specific antigen, cancer grade, number of positive biopsy cores, serum DHEA-S and C-reactive protein levels (Table S8). This revealed differences between AA and EA in Vitamin D, Total cholesterol, and Hba1c levels. A comparison of cancer patients based on race revealed significant differences in Vitamin D levels and not surprisingly the number of positive biopsy cores. A comparison of patients without prostate cancer based on race revealed total cholesterol as significantly different between AA and EA $(p=0.034)$ (Table S8).

Subsequently, we wished to determine if clinical phenotypes or patient characteristics correlated with the patient clusters from the heat map of gene expression focusing on the 187 gene signature (Figure 7) and exploring the cluster of five patients that were identified as extremal in the heat map.

Patient characteristics within the 2 patient clusters in Figure 7 are reported in Table 3. This extreme patient cluster was associated with race, Gleason score, number of positive biopsy punches, triglycerides, and CRP.

Table 3. Patient characteristics of the five most extreme AA patients compared to patients $(n=54)$ who did not cluster with these five patients.

\begin{tabular}{|c|c|c|c|}
\hline Most Extreme AA vs. Others & Others $(n=54)$ & Most Extreme AA $(n=5)$ & $p$ \\
\hline Age, years, mean (SD) & $65.4(6.37)$ & $60.0(8.32)$ & 0.125 \\
\hline Race, White, $n(\%)$ & $26(48.1)$ & $0(0.00)$ & 0.066 \\
\hline BMI, kg/m2, mean (SD) & $29.4(5.93)$ & $30.2(5.77)$ & 0.775 \\
\hline PSA, $(\mu \mathrm{g} / \mathrm{L})$, median (IQR) & $6.16(3.40)$ & $6.25(0.70)$ & 0.418 \\
\hline Cancer, Yes, No (\%) & $34(63.0)$ & $5(100.0)$ & 0.156 \\
\hline Gleason Score, median (IQR) & $6(7)$ & $7(0)$ & 0.046 \\
\hline Number Positive, median (IQR) & $1(3)$ & $6(5)$ & 0.010 \\
\hline \multicolumn{4}{|l|}{ Comorbidities, Yes, $n(\%)$} \\
\hline Coronary Artery Disease & $6(11.1)$ & $0(0.00)$ & 1.000 \\
\hline Hypertension & $35(64.8)$ & $3(60.0)$ & 1.000 \\
\hline Hypercholesterolemia & $41(75.9)$ & $3(60.0)$ & 0.593 \\
\hline Diabetes mellitus & $15(27.8)$ & $2(40.0)$ & 0.620 \\
\hline Depression & $8(14.8)$ & $1(20.0)$ & 0.577 \\
\hline Post-Traumatic Stress Disorder & $10(18.5)$ & $2(40.0)$ & 0.266 \\
\hline \multicolumn{4}{|l|}{ Patient Measures, mean (SD) } \\
\hline SBP & $136.0(17.1)$ & $138.2(26.6)$ & 0.794 \\
\hline DBP & $81.2(9.06)$ & $85.2(7.60)$ & 0.349 \\
\hline Heart Rate & $74.2(12.6)$ & $80.2(16.0)$ & 0.320 \\
\hline LDL & $122.8(36.4)$ & $97.0(50.1)$ & 0.146 \\
\hline Triglycerides & $111.5(51.5)$ & $141.4(31.3)$ & 0.073 \\
\hline Total Cholesterol & $192.1(39.7)$ & $176.2(56.5)$ & 0.413 \\
\hline WHR & $0.98(0.074)$ & $1.00(0.076)$ & 0.617 \\
\hline $\mathrm{A} 1 \mathrm{c}$ & $5.73(0.86)$ & $6.02(2.57)$ & 0.330 \\
\hline DHEA-S, median (IQR) & $114(91)$ & $279(173)$ & 0.211 \\
\hline Serum Creatinine & $1.04(0.22)$ & $1.03(0.28)$ & 0.944 \\
\hline Serum Albumin & $3.89(0.31)$ & $3.86(0.34)$ & 0.855 \\
\hline C-Reactive Protein & $0.50(0.81)$ & $0.24(0.11)$ & 0.035 \\
\hline Serum D3 levels & $31.0(14.2)$ & $20.3(13.3)$ & 0.112 \\
\hline Service Era, $n(\%)$ & & & 0.757 \\
\hline Vietnam & $38(70.4)$ & $3(60.0)$ & \\
\hline Post-Vietnam & $11(20.4)$ & $1(20.0)$ & \\
\hline Persian Gulf War & $5(9.26)$ & $1(20.0)$ & \\
\hline Agent Orange Exposure, Yes, $n(\%)$ & $10(18.5)$ & $1(20.0)$ & 1.000 \\
\hline Multivitamin Supplementation, Yes, $n(\%)$ & $19(35.2)$ & $0(0.0)$ & 0.165 \\
\hline Vitamin D Supplementation, Yes, $n(\%)$ & $15(27.8)$ & $0(0.0)$ & 0.316 \\
\hline Treatment Decision, $n(\%)$ & & & 0.291 \\
\hline Watchful Waiting & $3(5.56)$ & $0(0.00)$ & \\
\hline PSA Screening & $18(33.3)$ & $0(0.00)$ & \\
\hline Active Surveillance & $19(35.2)$ & $2(40.0)$ & \\
\hline XRT & $10(18.5)$ & $2(40.0)$ & \\
\hline Surgery & $4(7.41)$ & $1(20.0)$ & \\
\hline
\end{tabular}


The five patients at the extreme cluster in Figure 7 were all AA (100\% vs. $52.9 \%$ overall cohort, $p=0.066$ ). Patients in this extreme gene expression cluster also had higher Gleason scores, a greater number of positive biopsies, higher triglyceride levels, and lower CRP on average.

Patients clustering in this extreme cluster also had lower serum vitamin D levels (serum levels $<20 \mathrm{ng} / \mathrm{mL}$ ) and reported that they did not supplement with multivitamins, although these associations were not significant. Additionally, these five patients had elevated blood dehydroepiandrosterone sulfate (DHEAS) levels. A summary of the clinical characteristics of these five patients is provided in Table S9.

\section{Sparse Principal Component Analysis}

We next conducted a sparse principal component analysis (PCA) analysis of the expression patterns of the 187 genes using the R elasticnet package (Version 1.3) to identify potential subsets of stress signature genes associated with either patient prostate cancer status or with the 5 extreme patients identified by the heatmap (Figure 9). Sparse PCA is a specific technique widely used in statistical analysis and in the analysis of multivariate data sets such as this data. It extends classic PCA for the reduction of dimensionality of data by introducing sparsity structures to the input variables.
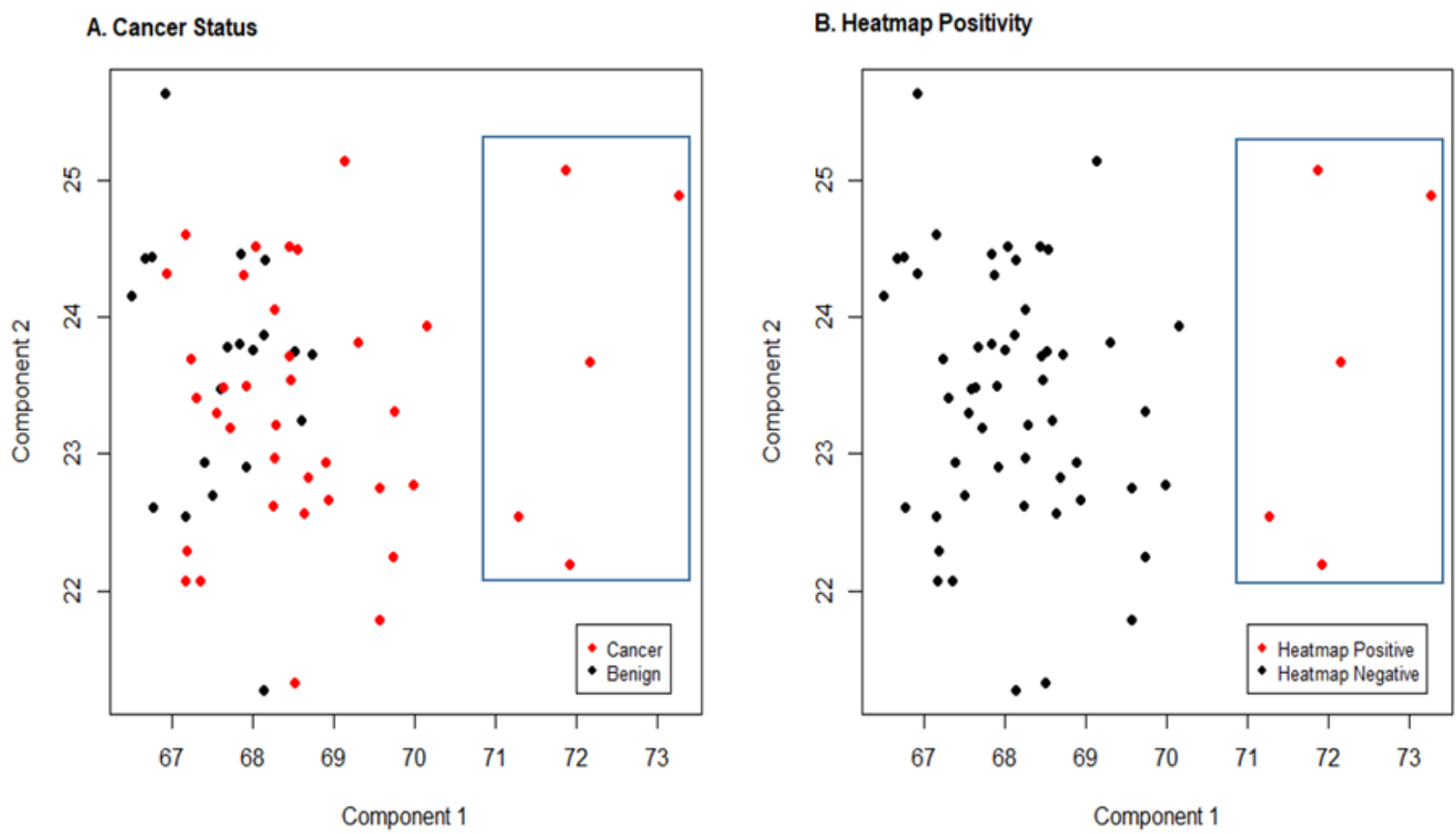

Figure 9. Sparse principal component analysis. Scatter plots of principal component 1 by component 2 from the sparse principal component analysis. (A) denotes values of these components by cancer status (red = cancer, black = benign). (B) denotes the 5 extreme patients identified by the heat map (Figure 7) in red versus all others in black. The blue rectangle in both plots highlights these five patients.

A particular disadvantage of ordinary PCA is that the principal components are usually linear combinations of all input variables. Sparse PCA overcomes this disadvantage by finding linear combinations that contain just a few input variables. Sparse PCA was thus desirable for this analysis as it not only allowed dimensionality reduction but also reduced the number of explicitly used variables. Furthermore, this approach has been previously validated for gene expression data where the number of variables or predictors ( $p$ ) (genes) is typically bigger than the number of samples $(n)$ (in this study $n=60, p=187$ ) [57]. 
Associations between the sparse PC with cancer status or with the 5 extreme patients were also examined to determine if the 187 gene signature was associated with patient outcome. The first component identified by sparse PCA included 54 of the 187 genes and the second component included 34 of the 187 genes. As noted above GO/pathway analysis of the 187 genes found that these genes map to RNA binding, structural constituent of the ribosome and translation. The majority of the 54 genes included in the first component mapped to translational functionality, though there was significant overlap with RNA binding and structural constituent of the ribosome.

Cancer status was significantly associated with the first component $(p=0.004)$ in patients who were cancer positive. Of note, 51 of the 54 genes in the first component had positive loadings and only 3 had negative loadings which in general suggests that the majority of genes included in the first component were more highly expressed in patients that were cancer positive.

We also examined the association of the components with the 5 extreme cancer patients identified by the heat map. The first component was strongly associated with these 5 patients $(p=0.000007)$ with these 5 patients showing the largest value for this component. Figure 9 provides plots of principal component 1 compared to principal component 2 with data highlighted by cancer status (Figure 9A) and for a comparison of the 5 extreme patients vs. all others, defined as heatmap positivity (Figure 9B). The five extreme patients are highlighted on both plots.

\section{Discussion}

An emerging hypothesis about cancer risk and outcomes in the context of racial disparities is that psychological and social stressors impact cellular stress responses [58,59]; however, limited empirical data are available on racial differences in cellular stress responses among men who are at risk for developing prostate cancer. Our prior work assessed transcriptomic differences between EA and AA who had undergone a prostatectomy, following a diagnosis of localized prostate cancer. This revealed AA with higher expression of genes associated with immune response and inflammation [28]. This study exploited RNA-Seq and focused on a cohort of men who had presented either with earlystage prostate cancer or were at risk for prostate cancer. The patient population was comprised of veterans attending the Urology Clinic at the Veterans Administration Medical Center because of an elevated serum level of prostate-specific antigen. At the Charleston VAMC, the breakdown of this population is essentially 50/50 African American/Caucasian. We enrolled $33 \mathrm{AA}$ and $27 \mathrm{EA}$ men, 60 subjects in total, who had undergone a prostate biopsy. Blood samples were acquired from each subject at enrollment. Standard pathology was performed according to protocol. Following the pathology assessment of the prostate biopsy, study subjects were categorized by Gleason score and other clinical parameters. Study tissue samples were placed in sterile tubes, de-identified and flash-frozen until RNA extraction was performed for RNA-Seq library construction. A paired end sequencing approach was undertaken. Differential expression analysis was carried out with DEseq2 and systems level analyses using gene enrichment and pathway impact analyses. Although the sample cohort examined was modest with 60 patients (33 AA and $27 \mathrm{EA}$ ), this analysis revealed significant differences between EA and AA, with 3277 genes significantly DE between the two racial groups.

Analysis of these DE transcripts revealed several significantly impacted pathways between EA and AA based on two forms of evidence over representation analysis, and perturbation analysis [60]. A recent study of gene expression changes in prostate cancer using data present in the Gene Expression Omnibus and The Cancer Genome Atlas databases identified $484 \mathrm{DE}$ genes in prostate cancer compared with adjacent normal tissue. The Neuroactive ligand-receptor interaction signaling pathway was one of the significantly impacted biological pathways between EA and AA [60]. The pathway comprises G-protein coupled receptors, ion channels and ligands which function in modulating neural plasticity, memory processes, and behavior. Previous studies have associated this signaling pathway 
with the development of bladder cancer and renal cell carcinoma [61,62]. A proteomics approach was undertaken recently by Myers et al. to compare EA and AA men. Similar to our findings they noted that this Neuroactive ligand-receptor interaction signaling pathway was enriched in prostate tumors in AA men [63]. Specific interactions between cells and the ECM are facilitated by integrins and proteoglycans, CD36, and other cell-surface-molecules. A recent study examined gene expression differences in prostate cancer tissue between EA and AA and revealed that the stroma was the site of aggressive changes [64].

Castration-resistant prostate cancer is a fatal form of the disease, which develops upon resistance to primary androgen deprivation therapy (ADT). The PI3K-AKT-mTOR signaling axis plays an important role in the development and upkeep of CRPC. This pathway is dysregulated in most advanced prostate cancer and enables cancer cells to overcome androgen deprivation related stress $[65,66]$. Powell and colleagues examined 639 tumor samples (270 AAM, 369 EAM) and demonstrated linkage of DE genes to roles inflammation and lipid metabolism. The PI3 kinase/Akt pathway is influential in prostate cancer development and is involved in pathway crosstalk interactions. PI3 kinase/Akt is upregulated with insulin resistance and hyperinsulinemia [67].

In prostate cancer increased phosphorylation (activation) of Akt can be used to predict disease recurrence [68,69]. In human prostate cells, Akt is activated by high expression of golgi membrane protein 1 (GOLM1) [70]. Higher expression of GOLM1 exhibited oncogenic effects with the activation of Akt being an oncogenic driver. The use of Akt inhibitors abrogates the oncogenic effects of GOLM1, which suggests a precision medicine target for patients with high GOLM1 expression [70-72]. GOLM1 mRNA expression is up regulated in $\mathrm{AA}(\mathrm{FC}+1.4, q=0.042)$ along with myosin VI $(M Y 06)(\mathrm{FC}+1.4, q=0.004)$ compared to EA. Both are golgi related genes that are in the Genes up regulated in prostate cancer co-expression signature (Figure 6).

Motor proteins are the engines that perform intracellular transport of proteins along filaments to their target destination [73]. The motor protein MYO6 is associated with transport from the golgi to the cell surface of proteins [74,75]. In prostate cancer tissues, MYO6 and GOLM1 are known to co-locate at the golgi [76]. Additionally, GOLM1 is associated with surface membrane protein transport and recycling growth factor responsive receptor tyrosine kinase (RTK) and epidermal growth factor receptor (EGFR) proteins between the golgi and cell surface in hepatocellular carcinoma [77]. Specifically, it was found that GOLM1 recycles the EGFR and RTK membrane proteins resulting in Akt activation with commensurate oncogenic activity and metastatic progression in hepatocellular carcinoma [77].

Given the higher expression levels of GOLM1 and MYO6 transcripts in AA relative to EA men (Figure 6) suggests Akt antagonism as a potential target for AA patients. The differential expression of MYO6 and GOLM1 in AA prostate cancer tissue suggests transport of RTK proteins and the resulting oncogenic activity of Akt might be a good target to treat the AA aggressive prostate cancer phenotype. Future work will involve determining if AA prostate cancer tissues exhibit progression and metastatic potential via activated Akt through RTK recycling mechanisms promoted by MYO6 and GOLM1.

The presence of nicotine addiction, taste and olfactory transduction and alcoholism were among significant pathways reported in Table S4 that are due to pathway crosstalk. This is a phenomenon through which a pathway influences another either directly through common genes or through inter-pathway signals or linkage. The crosstalk phenomenon is well known and has been reported in two landmark papers [78,79]. Olfactory receptors (ORs) are expressed not only in the sensory neurons of the olfactory epithelium, but also in other tissues including prostate where their exact functions remain to be fully elucidated [80].

Co-expression analysis, i.e., investigating the simultaneous expression of two or more genes revealed similarity between the genes DE between EA and AA men in our study to the co-expression signature 'Genes up regulated in prostate cancer samples' [81] (Figure 5). Pathway and GO analysis functional enrichment revealed an enrichment of 
GO terms related to RNA binding, structural constituent of the ribosome, SRP-dependent co-translational protein targeting to membrane, and L13a-mediated translational silencing of Ceruloplasmin expression. Many of the terms relating to RNA binding are suggestive of a primitive stress response, such as those found in lower organisms [82].

Structural constituent of the ribosome is defined as the involvement of molecules that maintain structural integrity of the ribosome, e.g., ribosomal protein or ribosomal RNA. The two ribosomal subunits are comprised of rRNA and protein [83]. Alterations in rRNA/binding proteins lead to alternative polyadenylation which modifies the length of $3^{\prime}$ untranslated regions ultimately shortening them, marking them for degradation and modifying binding sites contained within this region. This phenomenon has become an emerging hallmark of cancer [84,85]. A significant body of evidence indicates that alterations in ribosome biogenesis lead to malignant transformation and progression [86]. Both c-MYC and the components of the PI3K-mTORC1 signaling pathway mediate ribosome biogenesis. The tumor suppressor p53 is activated in response to ribosomal biogenesis stress [86].

RNA binding proteins have been shown in numerous studies to have differential expression or mutations leading to various malignancies including prostate cancer [87]. In primitive organisms the contribution of translational regulation to the control of gene expression is significant during stress response. The ability of mammalian cells to modulate global protein synthesis in response to cellular stress is essential for cell survival [88]. While modulation of protein synthesis is mediated by the regulation of eukaryotic initiation and elongation factors, RNA-binding proteins (RBPs) provide a crucial extra layer to posttranscriptional regulation and have a major influence on the robust cellular response to external stress. The stress response in eukaryotic cells often inhibits translation initiation and leads to the formation of cytoplasmic RNA-protein stress granules [89].

Ribosomes bind on the endoplasmic reticulum and translate RNA sequences into proteins through biosynthesis. The endoplasmic reticulum and golgi organelles work together to support the translation and transport to the cell surface of membrane proteins. The golgi receives these proteins from the endoplasmic reticulum and sorts them for trafficking to their destination [90]. The Translation, GO:0006412 category contains two genes related to the endoplasmic reticulum that have modestly higher expression in AA compared with EA (Figures 6 and 7): (1) the gene protein kinase-like endoplasmic reticulum kinase $(P E R K)(F C+1.2, q=0.022)$, and (2) the stress-associated endoplasmic reticulum protein 1 (SERP1) $(\mathrm{FC}+1.2, q=0.025)$.

Disruption of quality control mechanisms by pathological and physiological mechanisms results in the accumulation of misfolded or unfolded proteins followed by increased ER. PERK is part of the endoplasmic stress sensing system that modulates the unfolded protein response (UPR) [91]. When the endoplasmic reticulum is under stress, PERK inhibits ribosomal translation at the endoplasmic reticulum membrane and target proteins for degradation [92]. SERP1 is upregulated in response to the UPR and rescues membrane proteins during endoplasmic stress to complete their folding $[93,94]$. Taken together, the two endoplasmic reticulum stress transcripts are suggestive of a greater stress response in AA compared with EA, with membrane proteins potentially being stabilized during endoplasmic reticulum stress through SERP1. ER stress and related UPR has been recognized as a hallmark for various diseases including cancer, kidney injury, male infertility, and neurodegenerative diseases. Recent animal model and human studies have shown high cholesterol and ER stress as emerging factors involved in disease development [95]. A comparison of benign patients in this study based on race revealed total cholesterol as significantly different between AA and EA $(p=0.034)$. The field of hypercholesterolemia and ER stress and their contribution to disease progression continues to expand.

When we examined the transcripts that were driving functional enrichment of RNA binding, structural constituent of the ribosome, SRP-dependent co-translational protein targeting to membrane, and L13a-mediated translational silencing of Ceruloplasmin expression we noted that many of the genes were shared across these terms (Figure 6). We 
reduced this to a shared set of 187 gene set that mapped to these functional annotations and represented a differential stress signature between AA and EA. We examined the gene expression patterns in these 187 genes in all the patients in our patient. This highlighted differences in expression between the two racial groups for these 187 genes, on a patient-by-patient basis with many of the transcripts modestly up-regulated $(\geq 1.6)$ in AA compared to EA and small set modestly down-regulated in AA compared to EA $(\leq 1.6)$. In addition, we also observed an extremal cluster of five AA patients ( $8 \%$ of the cohort). When we examined the clinical characteristics of these extremal patients, we noted elevated Gleason scores, greater numbers of positive core biopsies, higher triglyceride levels, and lower CRP. We also noted diminished serum Vitamin D levels. This 187 gene expression signature defines these extremal patients with more severe clinical characteristics. We explored protein to protein interactions (PPIs) among these 187 proteins and developed biological networks to reduce the complexity and allow these PPIs to be visualized. This network provided a snapshot of the differences between AA and EA patients and revealed a high degree of interaction among these proteins suggesting a functional role for this differential stress signature (Figure 8). Functional analysis revealed that seven of these transcripts LARP1, PUM2, PABPC1, DDX6, DDX25, ELAVL1 and CAPRIN1 mapped to the GO: Cellular Component term cytoplasmic stress granule. Many of these proteins interact with HMGB1 and HMGB2 whose overexpression is linked to tumor progression, metastasis and poor prognosis [96]. HMGB proteins are localized in the nucleus, cytoplasm and are also secreted to the extracellular milieu following either active secretion by immune cells or passive release from necrotic cells. HMGB proteins are functionally related to cancer progression and $H M G B 1$ overexpression has been detected in cancerous cells of prostate epithelial origin [53]. Eleven of these transcripts mapped to the GeneSigDB co-expression signature Human Prostate ChoVega05 [54]. This signature derived from pure populations of prostate cancer cells obtained from cancer cells from fresh-frozen prostatectomy tissue. Finally, we examined these 187 proteins using the cBioportal for Cancer Genomics [55,56]. We assessed 4900 samples / 4687 patients across 14 studies encompassing prostate adenocarcinoma and prostate cancer and observed that these 187 genes were altered in 1308 (28\%) of queried patients and 1383 (28\%) of queried samples (Table S7 /Figure S1) indicating that this gene signature plays a functional role in prostate cancer progression.

In summary even with the modest size of this patient cohort, this genomic signature derived from a prostate biopsy allowed us to distinguish between AA and EA men. Furthermore, we observed a clear set of five outlier patients within the AA group based on this signature. The clinical characteristics of the five patients were characterized by higher Gleason scores, a greater number of positive biopsies, higher triglyceride levels, and lower CRP.

Limitations of this study were the small patient cohort size, and the fact that RNASeq profiling was performed on just one biopsy collected from each patient. Ideally two or more distant core biopsies collected from each patient would be preferable. However, as IRBs are highly protective of study subjects' safety, a request to obtain two or more distant core biopsies from each study subject for purposes of RNA-Seq would risk denial. Another limitation with this study is that the level of stress could not be assessed a priori because it would be greatly affected by the diagnosis (e.g., the Gleason score), the prognosis, and the family and social implications of the health status of each patient after a complete clinical assessment was performed. Any attempt to anticipate the sub-grouping of study subjects was not feasible and would have resulted in a biased approach to the enrollment process. Another limitation was the lack of sample homogeneity in Gleason scores and tumor grades in our comparisons. Homogeneity of samples is achievable in pre-clinical studies but is a major challenge in human studies such as this one. Final limitations and confounders were sampling of the patient biopsy material at different times and Illumina sequencing with two independent runs and flow cells. We corrected these potential confounders as a batch factor in our data analyses. Future work will focus on continued correlation with longitudinal 
clinical and transcriptome changes in these patients. This will further elucidate the relative importance of the transcriptional changes we report here.

\section{Materials and Methods}

\subsection{Human Subjects}

This study was authorized by the Institutional Review Board (IRB) at the Medical University of South Carolina (MUSC) and the Research and Development (R\&D) Committee of the Ralph H. Johnson VA Medical Center (VAMC), (reference number: Pro00058835). Informed consent was obtained from all subjects involved in the study. Participants in this study were recruited from the Urology Clinic at the Ralph H. Johnson Veteran's Affairs Medical Center. Men qualified to participate in this study were those who have undergone a medically indicated prostate biopsy procedure because of rising serum levels of the prostate-specific antigen (PSA), or to monitor a low-risk prostate cancer as part of the active surveillance standard of care. This differed from our previous study in which men were enrolled at the time of radical prostatectomy [28]. Patients were enrolled at the time of biopsy and underwent standard allostatic load measurements and completed a questionnaire to assess stress and social determinants. We enrolled 60 subjects (27 EA and 33 AA men), who had undergone a prostate biopsy. Blood samples were acquired from each subject (at enrollment) to measure among other variables serum levels of 25-hydroxyvitamin D3 [25(OH)D3]. A description of the patient demographics and relevant clinical characteristics is in Table 1.

Treatment decisions among the cohort included watchful waiting, PSA Screening, active surveillance, XRT, and surgery. Table 1 provides the characteristics of the subjects, distributions of their age and race, BMI, serum levels of $25(\mathrm{OH}) \mathrm{D} 3$, blood pressure, total cholesterol, serum HBA1C levels, blood PSA levels and the number of positive prostate biopsy cores.

For these patients, data on comorbidities, including presence of coronary artery disease, hypertension, hypercholesterolemia, diabetes mellitus, depression and post-traumatic stress disorder were available. Additionally, data on military service duty and era, Vietnam, Post-Vietnam, and Persian Gulf War tours were gathered in addition to determining whether the patients had been exposed to Agent Orange during their tours of duty. Patients were queried as whether they were supplementing with multivitamins or not.

\subsection{Tissue Sample Procurement and RNA Purification}

Standard pathology was performed according to protocol at the Ralph H. Johnson VAMC. Study tissue samples were placed in sterile tubes, de-identified and flash-frozen using liquid nitrogen, and transported to the Genomics Core Facility at MUSC Total RNA was purified using Qiagen RNeasy in accordance with the manufacturer's instructions. RNA integrity was assessed using the Agilent 2100 Bioanalyzer RNA 6000 Nano Assay chips (Agilent Technologies, Palo Alto, CA, USA).

\subsection{RNA Sequencing and Analyses}

$200 \mathrm{ng}$ of total RNA from a biopsy yield of 400-500 ng was used to construct RNA-Seq libraries using the TruSeq RNA Sample Prep Kit (Illumina, San Diego, CA, USA). High throughput sequencing (HTS) was performed using an Illumina HiSeq2500. Each sample was sequenced using a paired end approach to a depth of $\sim 60$ million reads or greater. Data were subjected to Illumina quality control (QC) procedures. Secondary analysis was performed as we have previously described using the Genomics Research Platform (OnRamp Bioinformatics, San Diego, CA, USA) [28,97]. The RNA-Seq workflow used to process the data included (1) fastq validation and quality control, (2) read alignment to the human genome (hg19) using the Spliced Transcripts Alignment to a Reference (STAR) Aligner [98], which revealed $>93 \%$ mapping of the PE reads, (3) extraction of gene-level count data using HTSeq, and (4) differential expression analysis with DEseq2 [47-49]. FDR was calculated using the Benjamini-Hochberg multiple testing adjustment procedure [99]. 
Statistical analysis of pathways and GO terms was performed using this sorted transcript list as we described $[100,101]$ and via gene set enrichment via ToppGene [51]. Venn diagrams were made using BioVenn [102]. In addition, we utilized iPathwayGuide to perform pathway analyses. Pathways were ranked using the Impact Analysis method [50,103,104]. Impact analysis utilizes two kinds of evidence: (i) the over-representation of DE genes from a particular pathway and (ii) the perturbation of that pathway measured by disseminating the measured expression changes across the topology of the pathway [105-108]. To address power, we used a sample size tool available in RNASeqPower (Figure 1) [46]. R version 4.0.0 software environment was used for all analyses [109].

\subsection{Heat Maps}

Heat maps were generated from count data normalized by the variance stabilizing transformation method using DESeq2 version 1.16.1 [49]. For comparison of EA and AA samples unsupervised hierarchical clustering was performed using gplots version 3.0.1. Guided by the hierarchical clustering patient data was subsequently ordered separating the AA from the EA samples and the up-regulated from the down-regulated genes. All heat maps for EA and AA comparisons were made using the same ordering scheme.

\subsection{Statistical Testing of Patient Characteristics and Clinical Phenotype}

Associations between the two patient clusters identified in the heat maps with continuous phenotypes/characteristics were examined using 2 sample $t$-tests or Wilcoxon rank sum tests when applicable and associations with categorical phenotypes were examined using a Fisher's exact test approach. Given the sample patient size, this analysis was considered exploratory and all associations with a $p<0.1$ were considered as potentially meaningful. Sparse PCA combines principal component analysis with a penalized regression approach which provides greater consistency in components relative to standard PCA when data are high dimensional $[110,111]$. Additionally, sparse PCA yields components with non-zero loadings on only a subset of the original predictors, thus simultaneously providing variable selection and dimension reduction [57]. We conducted a sparse PCA analysis of the 187 transcripts we identified as a shared gene signature from Pathway and $\mathrm{GO}$ analysis using the R elasticnet package (Version 1.3). Associations between the sparse PC with cancer status or with a stress phenotype identified by cluster analysis extreme patients were examined using logistic regression.

\subsection{Ethics Approval and Consent to Participate}

Informed consent was obtained from all subjects involved in the study. This study was authorized by the Institutional Review Board (IRB) at the Medical University of South Carolina (MUSC) and the Research and Development (R\&D) Committee of the Ralph H. Johnson VA Medical Center (VAMC). Participants in this study were recruited from the Urology Clinic at the Ralph H. Johnson Veteran's Affairs Medical Center.

\subsection{Availability of Data and Materials}

The data that support the findings of this study are available at National Center for Biotechnology Information (NCBI) Gene Expression Omnibus (GEO) database; accession number GSE138503; https: / / www.ncbi.nlm.nih.gov / geo / query / acc.cgi?acc=GSE138503, accessed on 12 October 2021.

\section{Conclusions}

Our goal in this study was to identify the systemic milieu in which prostate cancer develops and potentially progresses, especially as it relates to EA vs. AA. With this objective in mind, we interrogated the prostate transcriptome with a single biopsy core and examined for the first-time gene expression patterns relevant to prostate cancer differences between EA and AA men presenting with early-stage prostate cancer. Comparison across racial groupings uncovered differences in transcriptomic profiles. Transcriptomic analyses 
indicated a differential stress gene signature between AA and EA which allowed separation of patients with more severe clinical characteristics.

Supplementary Materials: The following are available online at https:/ /www.mdpi.com/article/10 .3390/ cancers13205143/s1, Table S1: PI3K-Akt signaling pathway (KEGG: 04151) Pathway Genes, Table S2: Neuroactive ligand-receptor interaction (KEGG: 04080) Pathway Genes, Table S3: ECMreceptor interaction (KEGG: 04512) Pathway Genes, Table S4: Functional enrichment of differences in prostate gene expression between EA and AA subjects, Table S5: 187 Gene Signature differentially expressed between EA and AA subjects, Table S6: Functional enrichment of the 187 Gene Signature, Table S7: cBioPortal analysis of the 187 Gene Signature, Table S8: Univariate differences in patient clinical characteristics, Table S9: Clinical characteristics of the five extremal patients, Figure S1: Analysis of the 187 gene signature using cBioPortal.

Author Contributions: Conceptualization, G.H., S.J.S., S.G.-C. and C.H.H.; Formal analysis, G.H., E.S.H., W.A.d.S., R.M., A.H., M.S.J., R.C.W., S.C., L.A., L.F., B.W. and C.H.H.; Funding acquisition, G.H., S.G.-C. and C.H.H.; Investigation, S.J.S., E.S.H., W.A.d.S., R.M., A.H., M.S.J., R.C.W., S.C., L.A., L.F., B.W., S.G.-C. and C.H.H.; Methodology, E.S.H., S.C., L.A., B.W. and S.G.-C.; Project administration, G.H., S.J.S., S.G.-C. and C.H.H.; Visualization, W.A.d.S., R.M., A.H. and M.S.J.; Writing-original draft, G.H.; Writing-review \& editing, G.H., S.J.S., E.S.H., W.A.d.S., R.M., A.H., M.S.J., R.C.W., S.C., L.A., L.F., B.W., S.G.-C. and C.H.H. All authors have read and agreed to the published version of the manuscript.

Funding: This research was funded by an NIH/NIMHD award to the Medical University of South Carolina Transdisciplinary Collaborative Center in Precision Medicine and Minority Men's Health (U54MD010706-CHH). The authors also acknowledge support from the Genomics Shared Resource, Hollings Cancer Center, Medical University of South Carolina. This shared resource is supported in part by the Hollings Cancer Center, Medical University of South Carolina Support Grant (P30 CA 138313). All authors reviewed and approved the manuscript. G.H. acknowledges support from NIH/NIDA 1U01DA045300-01A1 and start-up funding from Queens University Belfast.

Institutional Review Board Statement: This study was authorized by the Institutional Review Board (IRB) at the Medical University of South Carolina (MUSC) and the Research and Development (R\&D) Committee of the Ralph H. Johnson VA Medical Center (VAMC), reference number: Pro00058835.

Informed Consent Statement: Informed consent was obtained from all subjects involved in the study. Participants in this study were recruited from the Urology Clinic at the Ralph H. Johnson Veteran's Affairs Medical Center.

Data Availability Statement: The data that support the findings of this study are available at National Center for Biotechnology Information (NCBI) Gene Expression Omnibus (GEO) database; accession number GSE138503, https: / / www.ncbi.nlm.nih.gov / geo/ query / acc.cgi?acc=GSE138503, accessed on 12 October 2021.

Conflicts of Interest: The authors declare no conflict of interest. The funders had no role in the design of the study; in the collection, analyses, or interpretation of data; in the writing of the manuscript, or in the decision to publish the results.

\section{References}

1. Reagan, L.P.; Grillo, C.A.; Piroli, G.G. The As and Ds of stress: Metabolic, morphological and behavioral consequences. Eur. J. Pharmacol. 2008, 585, 64-75. [CrossRef]

2. Dhabhar, F.S.; Miller, A.H.; McEwen, B.S.; Spencer, R.L. Effects of stress on immune cell distribution. Dynamics and hormonal mechanisms. J. Immunol. 1995, 154, 5511-5527. [PubMed]

3. Dhabhar, F.S.; McEwen, B.S. Stress-induced enhancement of antigen-specific cell-mediated immunity. J. Immunol. 1996, 156, 2608-2615. [PubMed]

4. Miyashita, Y. Cognitive memory: Cellular and network machineries and their top-down control. Science 2004, 306, 435-440. [CrossRef] [PubMed]

5. McEwen, B.S.; Stellar, E. Stress and the individual. Mechanisms leading to disease. Arch. Intern. Med. 1993, $153,2093-2101$. [CrossRef] [PubMed]

6. Ogden, J. Health Psychology: A Textbook: A Textbook; McGraw-Hill Education: London, UK, 2012.

7. Seeman, T.; Epel, E.; Gruenewald, T.; Karlamangla, A.; McEwen, B.S. Socio-economic differentials in peripheral biology: Cumulative allostatic load. Ann. N. Y. Acad. Sci. 2010, 1186, 223-239. [CrossRef] [PubMed] 
8. Szanton, S.L.; Gill, J.M.; Allen, J.K. Allostatic load: A mechanism of socioeconomic health disparities? Biol. Res. Nurs. 2005, 7, 7-15. [CrossRef] [PubMed]

9. Karlamangla, A.; Gruenewald, T.; Seeman, T. Promise of biomarkers in assessing and predicting health. In The Biological Consequences of Socioeconomic Inequalities; Wolfe, B., Evans, W., Seeman, T., Eds.; Russell Sage Foundation: New York, NY, USA, 2012; pp. 38-62.

10. Lu, S.; Wei, F.; Li, G. The evolution of the concept of stress and the framework of the stress system. Cell Stress 2011, 5, 76. [CrossRef]

11. Burroughs Peña, M.S.; Mbassa, R.S.; Slopen, N.B.; Williams, D.R.; Buring, J.E.; Albert, M.A. Cumulative Psychosocial Stress and Ideal Cardiovascular Health in Older Women. Circulation 2019, 139, 2012-2021. [CrossRef]

12. Elliott, B.; Zackery, D.L.; Eaton, V.A.; Jones, R.T.; Abebe, F.; Ragin, C.C.; Khan, S.A. Ethnic differences in TGFbeta-signaling pathway may contribute to prostate cancer health disparity. Carcinogenesis 2018, 39, 546-555. [CrossRef]

13. Siegel, R.L.; Miller, K.D.; Jemal, A. Cancer statistics, 2016. CA Cancer J. Clin. 2016, 66, 7-30. [CrossRef]

14. Bhardwaj, A.; Srivastava, S.K.; Khan, M.A.; Prajapati, V.K.; Singh, S.; Carter, J.E.; Singh, A.P. Racial disparities in prostate cancer: A molecular perspective. Front. Biosci. (Landmark Ed.) 2017, 22, 772-782. [CrossRef]

15. Lim, L.S.; Sherin, K. Screening for prostate cancer in U.S. men ACPM position statement on preventive practice. Am. J. Prev. Med. 2008, 34, 164-170. [CrossRef]

16. Freedland, S.J.; Sutter, M.E.; Naitoh, J.; Dorey, F.; Csathy, G.S.; Aronson, W.J. Clinical characteristics in black and white men with prostate cancer in an equal access medical center. Urology 2000, 55, 387-390. [CrossRef]

17. Freedland, S.J.; Amling, C.L.; Dorey, F.; Kane, C.J.; Presti, J.C., Jr.; Terris, M.K.; Aronson, W.J. Race as an outcome predictor after radical prostatectomy: Results from the Shared Equal Access Regional Cancer Hospital (SEARCH) database. Urology 2002, 60, 670-674. [CrossRef]

18. Waxman, A.J.; Mink, P.J.; Devesa, S.S.; Anderson, W.F.; Weiss, B.M.; Kristinsson, S.Y.; McGlynn, K.A.; Landgren, O. Racial disparities in incidence and outcome in multiple myeloma: A population-based study. Blood 2010, 116, 5501-5506. [CrossRef]

19. Smith, C.J.; Ambs, S.; Landgren, O. Biological determinants of health disparities in multiple myeloma. Blood Cancer J. 2018, 8, 85. [CrossRef]

20. Cui, Y.S.; Song, Y.P.; Fang, B.J. The role of long non-coding RNAs in multiple myeloma. Eur. J. Haematol. 2019, 103, 3-9. [CrossRef]

21. Kazandjian, D. Multiple myeloma epidemiology and survival: A unique malignancy. Semin Oncol. 2016, 43, 676-681. [CrossRef]

22. Wallace, K.; Li, H.; Brazeal, J.G.; Lewin, D.N.; Sun, S.; Ba, A.; Paulos, C.M.; Rachidi, S.; Li, Z.; Alekseyenko, A.V. Platelet and hemoglobin count at diagnosis are associated with survival in African American and Caucasian patients with colorectal cancer. Cancer Epidemiol. 2020, 67, 101746. [CrossRef]

23. Chatterjee, N.A.; He, Y.; Keating, N.L. Racial differences in breast cancer stage at diagnosis in the mammography era. Am. J. Public Health 2013, 103, 170-176. [CrossRef] [PubMed]

24. Gupta, V.; Haque, I.; Chakraborty, J.; Graff, S.; Banerjee, S.; Banerjee, S.K. Racial disparity in breast cancer: Can it be mattered for prognosis and therapy. J. Cell Commun. Signal. 2018, 12, 119-132. [CrossRef]

25. DeSantis, C.E.; Miller, K.D.; Goding Sauer, A.; Jemal, A.; Siegel, R.L. Cancer statistics for African Americans, 2019. CA Cancer J. Clin. 2019, 69, 211-233. [CrossRef]

26. Rebbeck, T.R.; Devesa, S.S.; Chang, B.L.; Bunker, C.H.; Cheng, I.; Cooney, K.; Eeles, R.; Fernandez, P.; Giri, V.N.; Gueye, S.M.; et al. Global patterns of prostate cancer incidence, aggressiveness, and mortality in men of african descent. Prostate Cancer 2013, 2013, 560857. [CrossRef] [PubMed]

27. Jones, A.L.; Chinegwundoh, F. Update on prostate cancer in black men within the UK. Ecancermedicalscience 2014, 8, 455. [CrossRef] [PubMed]

28. Hardiman, G.; Savage, S.J.; Hazard, E.S.; Wilson, R.C.; Courtney, S.M.; Smith, M.T.; Hollis, B.W.; Halbert, C.H.; GattoniCelli, S. Systems analysis of the prostate transcriptome in African-American men compared with European-American men. Pharmacogenomics 2016, 17, 1129-1143. [CrossRef] [PubMed]

29. Richards, Z.; Batai, K.; Farhat, R.; Shah, E.; Makowski, A.; Gann, P.H.; Kittles, R.; Nonn, L. Prostatic compensation of the vitamin $\mathrm{D}$ axis in African American men. JCI Insight 2017, 2, e91054. [CrossRef] [PubMed]

30. Benafif, S.; Kote-Jarai, Z.; Eeles, R.A.; Consortium, P. A Review of Prostate Cancer Genome-Wide Association Studies (GWAS). Cancer Epidemiol. Biomark. Prev. 2018, 27, 845-857. [CrossRef]

31. Barrington, W.E.; Schenk, J.M.; Etzioni, R.; Arnold, K.B.; Neuhouser, M.L.; Thompson, I.M., Jr.; Lucia, M.S.; Kristal, A.R. Difference in Association of Obesity With Prostate Cancer Risk Between US African American and Non-Hispanic White Men in the Selenium and Vitamin E Cancer Prevention Trial (SELECT). JAMA Oncol. 2015, 1, 342-349. [CrossRef]

32. Xiao, J.; Cohen, P.; Stern, M.C.; Odedina, F.; Carpten, J.; Reams, R. Mitochondrial biology and prostate cancer ethnic disparity. Carcinogenesis 2018, 39, 1311-1319. [CrossRef]

33. Yuan, J.; Kensler, K.H.; Hu, Z.; Zhang, Y.; Zhang, T.; Jiang, J.; Xu, M.; Pan, Y.; Long, M.; Montone, K.T.; et al. Integrative comparison of the genomic and transcriptomic landscape between prostate cancer patients of predominantly African or European genetic ancestry. PLoS Genet. 2020, 16, e1008641. [CrossRef]

34. Rebbeck, T.R. Prostate Cancer Genetics: Variation by Race, Ethnicity, and Geography. Semin Radiat Oncol. 2017, 27, 3-10. [CrossRef] 
35. Freedman, M.L.; Haiman, C.A.; Patterson, N.; McDonald, G.J.; Tandon, A.; Waliszewska, A.; Penney, K.; Steen, R.G.; Ardlie, K.; John, E.M.; et al. Admixture mapping identifies 8q24 as a prostate cancer risk locus in African-American men. Proc. Natl. Acad. Sci. USA 2006, 103, 14068-14073. [CrossRef]

36. Robbins, C.M.; Hooker, S.; Kittles, R.A.; Carpten, J.D. EphB2 SNPs and sporadic prostate cancer risk in African American men. PLoS ONE 2011, 6, e19494. [CrossRef]

37. Rawla, P. Epidemiology of Prostate Cancer. World J. Oncol. 2019, 10, 63-89. [CrossRef]

38. Matejcic, M.; Saunders, E.J.; Dadaev, T.; Brook, M.N.; Wang, K.; Sheng, X.; Olama, A.A.A.; Schumacher, F.R.; Ingles, S.A.; Govindasami, K.; et al. Germline variation at 8q24 and prostate cancer risk in men of European ancestry. Nat. Commun. 2018, 9, 4616. [CrossRef]

39. Schwartz, G.G. Vitamin D and the epidemiology of prostate cancer. Semin Dial. 2005, 18, 276-289. [CrossRef]

40. Looker, A.C.; Pfeiffer, C.M.; Lacher, D.A.; Schleicher, R.L.; Picciano, M.F.; Yetley, E.A. Serum 25-hydroxyvitamin D status of the US population: 1988-1994 compared with 2000-2004. Am. J. Clin. Nutr. 2008, 88, 1519-1527. [CrossRef]

41. Nesby-O’Dell, S.; Scanlon, K.S.; Cogswell, M.E.; Gillespie, C.; Hollis, B.W.; Looker, A.C.; Allen, C.; Doughertly, C.; Gunter, E.W.; Bowman, B.A. Hypovitaminosis D prevalence and determinants among African American and white women of reproductive age: Third National Health and Nutrition Examination Survey, 1988-1994. Am. J. Clin. Nutr. 2002, 76, 187-192. [CrossRef]

42. Garrett-Mayer, E.; Wagner, C.L.; Hollis, B.W.; Kindy, M.S.; Gattoni-Celli, S. Vitamin D3 supplementation (4000 IU/d for 1 y) eliminates differences in circulating 25-hydroxyvitamin D between African American and white men. Am. J. Clin. Nutr. 2012, 96, 332-336. [CrossRef]

43. Marshall, D.T.; Savage, S.J.; Garrett-Mayer, E.; Keane, T.E.; Hollis, B.W.; Horst, R.L.; Ambrose, L.H.; Kindy, M.S.; Gattoni-Celli, S. Vitamin D3 supplementation at 4000 international units per day for one year results in a decrease of positive cores at repeat biopsy in subjects with low-risk prostate cancer under active surveillance. J. Clin. Endocrinol Metab. 2012, 97, 2315-2324. [CrossRef]

44. Hollis, B.W.; Marshall, D.T.; Savage, S.J.; Garrett-Mayer, E.; Kindy, M.S.; Gattoni-Celli, S. Vitamin D3 supplementation, low-risk prostate cancer, and health disparities. J. Steroid Biochem. Mol. Biol. 2013, 136, 233-237. [CrossRef]

45. Woods-Burnham, L.; Cajigas-Du Ross, C.K.; Love, A.; Basu, A.; Sanchez-Hernandez, E.S.; Martinez, S.R.; Ortiz-Hernández, G.L.; Stiel, L.; Durán, A.M.; Wilson, C.; et al. Glucocorticoids Induce Stress Oncoproteins Associated with Therapy-Resistance in African American and European American Prostate Cancer Cells. Sci. Rep. 2018, 8, 15063. [CrossRef]

46. Hart, S.N.; Therneau, T.M.; Zhang, Y.; Poland, G.A.; Kocher, J.P. Calculating sample size estimates for RNA sequencing data. J. Comput. Biol. 2013, 20, 970-978. [CrossRef]

47. Anders, S.; McCarthy, D.J.; Chen, Y.; Okoniewski, M.; Smyth, G.K.; Huber, W.; Robinson, M.D. Count-based differential expression analysis of RNA sequencing data using R and Bioconductor. Nat. Protoc. 2013, 8, 1765-1786. [CrossRef]

48. Anders, S.; Huber, W. Differential expression analysis for sequence count data. Genome Biol. 2010, 11, R106. [CrossRef]

49. Love, M.I.; Huber, W.; Anders, S. Moderated estimation of fold change and dispersion for RNA-seq data with DESeq2. Genome Biol. 2014, 15, 550. [CrossRef]

50. Draghici, S.; Khatri, P.; Tarca, A.L.; Amin, K.; Done, A.; Voichita, C.; Georgescu, C.; Romero, R. A systems biology approach for pathway level analysis. Genome Res. 2007, 17, 1537-1545. [CrossRef]

51. Chen, J.; Bardes, E.E.; Aronow, B.J.; Jegga, A.G. ToppGene Suite for gene list enrichment analysis and candidate gene prioritization. Nucleic Acids Res. 2009, 37, W305-W311. [CrossRef] [PubMed]

52. Barreiro-Alonso, A.; Lamas-Maceiras, M.; García-Díaz, R.; Rodríguez-Belmonte, E.; Yu, L.; Pardo, M.; Choudhary, J.S.; Cerdán, M.E. Delineating the HMGB1 and HMGB2 interactome in prostate and ovary epithelial cells and its relationship with cancer. Oncotarget 2018, 9, 19050-19064. [CrossRef] [PubMed]

53. Zhao, C.B.; Bao, J.M.; Lu, Y.J.; Zhao, T.; Zhou, X.H.; Zheng, D.Y.; Zhao, S.C. Co-expression of RAGE and HMGB1 is associated with cancer progression and poor patient outcome of prostate cancer. Am. J. Cancer Res. 2014, 4, 369-377. [CrossRef] [PubMed]

54. Cho-Vega, J.H.; Troncoso, P.; Do, K.A.; Rago, C.; Wang, X.; Tsavachidis, S.; Medeiros, L.J.; Spurgers, K.; Logothetis, C.; McDonnell, T.J. Combined laser capture microdissection and serial analysis of gene expression from human tissue samples. Mod. Pathol. 2005, 18, 577-584. [CrossRef] [PubMed]

55. Cerami, E.; Gao, J.; Dogrusoz, U.; Gross, B.E.; Sumer, S.O.; Aksoy, B.A.; Jacobsen, A.; Byrne, C.J.; Heuer, M.L.; Larsson, E.; et al. The cBio cancer genomics portal: An open platform for exploring multidimensional cancer genomics data. Cancer Discov. 2012, 2, 401-404. [CrossRef] [PubMed]

56. Gao, J.; Aksoy, B.A.; Dogrusoz, U.; Dresdner, G.; Gross, B.; Sumer, S.O.; Sun, Y.; Jacobsen, A.; Sinha, R.; Larsson, E.; et al. Integrative analysis of complex cancer genomics and clinical profiles using the cBioPortal. Sci. Signal. 2013, 6, p11. [CrossRef] [PubMed]

57. Zou, H.; Hastie, T.; Tibshirani, R. Sparse Principal Component Analysis. J. Comput. Graph. Stat. 2006, 15, 265-286. [CrossRef]

58. Linnenbringer, E.; Gehlert, S.; Geronimus, A.T. Black-White Disparities in Breast Cancer Subtype: The Intersection of Socially Patterned Stress and Genetic Expression. AIMS Public Health 2017, 4, 526-556. [CrossRef]

59. Williams, D.R.; Mohammed, S.A. Discrimination and racial disparities in health: Evidence and needed research. J. Behav. Med. 2009, 32, 20-47. [CrossRef]

60. He, Z.; Tang, F.; Lu, Z.; Huang, Y.; Lei, H.; Li, Z.; Zeng, G. Analysis of differentially expressed genes, clinical value and biological pathways in prostate cancer. Am. J. Transl. Res. 2018, 10, 1444-1456. 
61. Fang, Z.Q.; Zang, W.D.; Chen, R.; Ye, B.W.; Wang, X.W.; Yi, S.H.; Chen, W.; He, F.; Ye, G. Gene expression profile and enrichment pathways in different stages of bladder cancer. Genet. Mol. Res. GMR 2013, 12, 1479-1489. [CrossRef]

62. Liu, X.; Wang, J.; Sun, G. Identification of key genes and pathways in renal cell carcinoma through expression profiling data. Kidney Blood Press. Res. 2015, 40, 288-297. [CrossRef]

63. Myers, J.S.; von Lersner, A.K.; Sang, Q.-X.A. Proteomic upregulation of fatty acid synthase and fatty acid binding protein 5 and identification of cancer-and race-specific pathway associations in human prostate cancer tissues. J. Cancer 2016, 7, 1452. [CrossRef]

64. Kinseth, M.A.; Jia, Z.; Rahmatpanah, F.; Sawyers, A.; Sutton, M.; Wang-Rodriguez, J.; Mercola, D.; McGuire, K.L. Expression differences between African American and Caucasian prostate cancer tissue reveals that stroma is the site of aggressive changes. Int. J. Cancer 2014, 134, 81-91. [CrossRef]

65. Edlind, M.P.; Hsieh, A.C. PI3K-AKT-mTOR signaling in prostate cancer progression and androgen deprivation therapy resistance. Asian J. Androl. 2014, 16, 378-386. [CrossRef]

66. Crumbaker, M.; Khoja, L.; Joshua, A.M. AR Signaling and the PI3K Pathway in Prostate Cancer. Cancers 2017, 9, 34. [CrossRef]

67. Dasgupta, S.; Srinidhi, S.; Vishwanatha, J.K. Oncogenic activation in prostate cancer progression and metastasis: Molecular insights and future challenges. J. Carcinog. 2012, 11, 4. [CrossRef]

68. Kreisberg, J.I.; Malik, S.N.; Prihoda, T.J.; Bedolla, R.G.; Troyer, D.A.; Kreisberg, S.; Ghosh, P.M. Phosphorylation of Akt (Ser473) is an excellent predictor of poor clinical outcome in prostate cancer. Cancer Res. 2004, 64, 5232-5236. [CrossRef]

69. Bedolla, R.; Prihoda, T.J.; Kreisberg, J.I.; Malik, S.N.; Krishnegowda, N.K.; Troyer, D.A.; Ghosh, P.M. Determining risk of biochemical recurrence in prostate cancer by immunohistochemical detection of PTEN expression and Akt activation. Clin. Cancer Res. An. Off. J. Am. Assoc. Cancer Res. 2007, 13, 3860-3867. [CrossRef]

70. Yan, G.; Ru, Y.; Wu, K.; Yan, F.; Wang, Q.; Wang, J.; Pan, T.; Zhang, M.; Han, H.; Li, X.; et al. GOLM1 promotes prostate cancer progression through activating PI3K-AKT-mTOR signaling. Prostate 2018, 78, 166-177. [CrossRef]

71. Frey, L.J.; Bernstam, E.V.; Denny, J.C. Precision medicine informatics. J. Am. Med. Inform. Assoc. JAMIA 2016, 23, 668-670. [CrossRef]

72. Bitting, R.L.; Armstrong, A.J. Targeting the PI3K/Akt/mTOR pathway in castration-resistant prostate cancer. Endocr.-Relat. Cancer 2013, 20, R83-R99. [CrossRef]

73. Vale, R.D. The molecular motor toolbox for intracellular transport. Cell 2003, 112, 467-480. [CrossRef]

74. Sahlender, D.A.; Roberts, R.C.; Arden, S.D.; Spudich, G.; Taylor, M.J.; Luzio, J.P.; Kendrick-Jones, J.; Buss, F. Optineurin links myosin VI to the Golgi complex and is involved in Golgi organization and exocytosis. J. Cell Biol. 2005, 169, 285-295. [CrossRef] [PubMed]

75. Rock, R.S.; Rice, S.E.; Wells, A.L.; Purcell, T.J.; Spudich, J.A.; Sweeney, H.L. Myosin VI is a processive motor with a large step size. Proc. Natl. Acad. Sci. USA 2001, 98, 13655-13659. [CrossRef] [PubMed]

76. Wei, S.; Dunn, T.A.; Isaacs, W.B.; De Marzo, A.M.; Luo, J. GOLPH2 and MYO6: Putative prostate cancer markers localized to the Golgi apparatus. Prostate 2008, 68, 1387-1395. [CrossRef]

77. Ye, Q.H.; Zhu, W.W.; Zhang, J.B.; Qin, Y.; Lu, M.; Lin, G.L.; Guo, L.; Zhang, B.; Lin, Z.H.; Roessler, S.; et al. GOLM1 Modulates EGFR/RTK Cell-Surface Recycling to Drive Hepatocellular Carcinoma Metastasis. Cancer Cell 2016, 30, 444-458. [CrossRef]

78. Donato, M.; Xu, Z.; Tomoiaga, A.; Granneman, J.G.; Mackenzie, R.G.; Bao, R.; Than, N.G.; Westfall, P.H.; Romero, R.; Draghici, S. Analysis and correction of crosstalk effects in pathway analysis. Genome Res. 2013, 23, 1885-1893. [CrossRef]

79. Tomoiaga, A.; Westfall, P.; Donato, M.; Draghici, S.; Hassan, S.; Romero, R.; Tellaroli, P. Pathway crosstalk effects: Shrinkage and disentanglement using a Bayesian hierarchical model. Stat. Biosci. 2016, 8, 374-394. [CrossRef]

80. Neuhaus, E.M.; Zhang, W.; Gelis, L.; Deng, Y.; Noldus, J.; Hatt, H. Activation of an olfactory receptor inhibits proliferation of prostate cancer cells. J. Biol. Chem. 2009, 284, 16218-16225. [CrossRef]

81. Liu, P.; Ramachandran, S.; Ali Seyed, M.; Scharer, C.D.; Laycock, N.; Dalton, W.B.; Williams, H.; Karanam, S.; Datta, M.W.; Jaye, D.L.; et al. Sex-determining region $\mathrm{Y}$ box 4 is a transforming oncogene in human prostate cancer cells. Cancer Res. 2006, 66, 4011-4019. [CrossRef]

82. Alves, L.R.; Goldenberg, S. RNA-binding proteins related to stress response and differentiation in protozoa. World J. Biol. Chem. 2016, 7, 78-87. [CrossRef]

83. De la Cruz, J.; Karbstein, K.; Woolford, J.L., Jr. Functions of ribosomal proteins in assembly of eukaryotic ribosomes in vivo. Annu. Rev. Biochem. 2015, 84, 93-129. [CrossRef]

84. Lin, Y.; Li, Z.; Ozsolak, F.; Kim, S.W.; Arango-Argoty, G.; Liu, T.T.; Tenenbaum, S.A.; Bailey, T.; Monaghan, A.P.; Milos, P.M.; et al. An in-depth map of polyadenylation sites in cancer. Nucleic Acids Res. 2012, 40, 8460-8471. [CrossRef]

85. Han, T.; Kim, J.K. Driving glioblastoma growth by alternative polyadenylation. Cell Res. 2014, 24, 1023. [CrossRef]

86. Golomb, L.; Volarevic, S.; Oren, M. p53 and ribosome biogenesis stress: The essentials. FEBS Lett. 2014, 588, 2571-2579. [CrossRef]

87. Vaarala, M.H.; Porvari, K.S.; Kyllönen, A.P.; Mustonen, M.V.; Lukkarinen, O.; Vihko, P.T. Several genes encoding ribosomal proteins are over-expressed in prostate-cancer cell lines: Confirmation of L7a and L37 over-expression in prostate-cancer tissue samples. Int. J. Cancer 1998, 78, 27-32. [CrossRef]

88. Harvey, R.; Dezi, V.; Pizzinga, M.; Willis, A.E. Post-transcriptional control of gene expression following stress: The role of RNA-binding proteins. Biochem. Soc. Trans. 2017, 45, 1007-1014. [CrossRef]

89. Buchan, J.R.; Parker, R. Eukaryotic stress granules: The ins and outs of translation. Mol. Cell 2009, 36, 932-941. [CrossRef] 
90. Pulvirenti, T.; Giannotta, M.; Capestrano, M.; Capitani, M.; Pisanu, A.; Polishchuk, R.S.; San Pietro, E.; Beznoussenko, G.V.; Mironov, A.A.; Turacchio, G.; et al. A traffic-activated Golgi-based signalling circuit coordinates the secretory pathway. Nat. Cell Biol. 2008, 10, 912-922. [CrossRef]

91. Harding, H.P.; Novoa, I.; Zhang, Y.; Zeng, H.; Wek, R.; Schapira, M.; Ron, D. Regulated translation initiation controls stressinduced gene expression in mammalian cells. Mol. Cell 2000, 6, 1099-1108. [CrossRef]

92. Ron, D.; Walter, P. Signal integration in the endoplasmic reticulum unfolded protein response. Nat. Rev. Mol. Cell Biol. 2007, 8, 519-529. [CrossRef]

93. Lee, A.H.; Iwakoshi, N.N.; Glimcher, L.H. XBP-1 regulates a subset of endoplasmic reticulum resident chaperone genes in the unfolded protein response. Mol. Cell. Biol. 2003, 23, 7448-7459. [CrossRef]

94. Yamaguchi, A.; Hori, O.; Stern, D.M.; Hartmann, E.; Ogawa, S.; Tohyama, M. Stress-associated endoplasmic reticulum protein 1 (SERP1)/Ribosome-associated membrane protein 4 (RAMP4) stabilizes membrane proteins during stress and facilitates subsequent glycosylation. J. Cell Biol. 1999, 147, 1195-1204. [CrossRef]

95. Sozen, E.; Ozer, N.K. Impact of high cholesterol and endoplasmic reticulum stress on metabolic diseases: An updated mini-review. Redox Biol. 2017, 12, 456-461. [CrossRef]

96. Lange, S.S.; Vasquez, K.M. HMGB1: The jack-of-all-trades protein is a master DNA repair mechanic. Mol. Carcinog 2009, 48, 571-580. [CrossRef] [PubMed]

97. Davis-Turak, J.; Courtney, S.M.; Hazard, E.S.; Glen, W.B., Jr.; da Silveira, W.A.; Wesselman, T.; Harbin, L.P.; Wolf, B.J.; Chung, D.; Hardiman, G. Genomics pipelines and data integration: Challenges and opportunities in the research setting. Expert Rev. Mol. Diagn 2017, 17, 225-237. [CrossRef] [PubMed]

98. Dobin, A.; Davis, C.A.; Schlesinger, F.; Drenkow, J.; Zaleski, C.; Jha, S.; Batut, P.; Chaisson, M.; Gingeras, T.R. STAR: Ultrafast universal RNA-seq aligner. Bioinformatics 2013, 29, 15-21. [CrossRef] [PubMed]

99. Benjamini, Y.; Hochberg, Y. Controlling the false discovery rate: A practical and powerful approach to multiple testing. J. R. Stat. Soc. Ser. B (Methodol.) 1995, 289-300. [CrossRef]

100. Kozak, I.; Sasik, R.; Freeman, W.R.; Sprague, L.J.; Gomez, M.L.; Cheng, L.; El-Emam, S.; Mojana, F.; Bartsch, D.U.; Bosten, J.; et al. A degenerative retinal process in HIV-associated non-infectious retinopathy. PLoS ONE 2013, 8, e74712. [CrossRef]

101. Paolini, P.; Pick, D.; Lapira, J.; Sannino, G.; Pasqualini, L.; Ludka, C.; Sprague, L.J.; Zhang, X.; Bartolotta, E.A.; Vazquez-Hidalgo, E.; et al. Developmental and extracellular matrix-remodeling processes in rosiglitazone-exposed neonatal rat cardiomyocytes. Pharmacogenomics 2014, 15, 759-774. [CrossRef]

102. Hulsen, T.; de Vlieg, J.; Alkema, W. BioVenn-A web application for the comparison and visualization of biological lists using area-proportional Venn diagrams. BMC Genom. 2008, 9, 488. [CrossRef]

103. Tarca, A.L.; Draghici, S.; Khatri, P.; Hassan, S.S.; Mittal, P.; Kim, J.-S.; Kim, C.J.; Kusanovic, J.P.; Romero, R. A novel signaling pathway impact analysis. Bioinformatics 2009, 25, 75-82. [CrossRef]

104. Khatri, P.; Sirota, M.; Butte, A.J. Ten Years of Pathway Analysis: Current Approaches and Outstanding Challenges. PLoS Comput. Biol. 2012, 8, e1002375. [CrossRef]

105. Kanehisa, M.; Sato, Y.; Kawashima, M.; Furumichi, M.; Tanabe, M. KEGG as a reference resource for gene and protein annotation. Nucleic Acids Res. 2016, 44, D457-D462. [CrossRef]

106. Kanehisa, M.; Goto, S.; Sato, Y.; Kawashima, M.; Furumichi, M.; Tanabe, M. Data, information, knowledge and principle: Back to metabolism in KEGG. Nucleic Acids Res. 2014, 42, D199-D205. [CrossRef]

107. Kanehisa, M.; Goto, S.; Furumichi, M.; Tanabe, M.; Hirakawa, M. KEGG for representation and analysis of molecular networks involving diseases and drugs. Nucleic Acids Res. 2010, 38, D355-D360. [CrossRef]

108. Kanehisa, M.; Goto, S. KEGG: Kyoto encyclopedia of genes and genomes. Nucleic Acids Res. 2000, 28, 27-30. [CrossRef]

109. Team, R.C. R: The R Project for Statistical Computing. 2019. Available online: https://www.r-project.org/ (accessed on 30 March 2020).

110. Shen, D.; Shen, H.; Marron, J.S. Consistency of sparse PCA in High Dimension, Low Sample Size contexts. J. Multivar. Anal. 2013, 115, 317-333. [CrossRef]

111. Shen, H.; Huang, J.Z. Sparse principal component analysis via regularized low rank matrix approximation. J. Multivar. Anal. 2008, 99, 1015-1034. [CrossRef] 